\title{
An Atom Probe Study on Nb Solute Partitioning and Nanocrystalline Grain Stabilization in Mechanically Alloyed Cu-Nb
}

Monica Kapoor ${ }^{1 *}$, Tyler Kaub ${ }^{1}$, Kristopher A. Darling ${ }^{2}$, Brad L. Boyce ${ }^{3}$, Gregory B. Thompson $^{1}$

${ }^{*}$ Corresponding Author

${ }^{1}$ University of Alabama, Department of Metallurgical \& Materials Engineering, Tuscaloosa, AL. 35487-0202, USA.

${ }^{2}$ U.S. Army Research Laboratory, Weapons and Materials Research Directorate, Aberdeen Proving Ground, MD. 21005-5069, USA.

${ }^{3}$ Sandia National Laboratories, Albuquerque, NM. 87123, USA.

Monica Kapoor is currently at U.S. Department of Energy's National Energy Technology Laboratory, Structural Materials Group, Albany, OR. 97321, USA.

\section{Email Address}

Monica Kapoor - mkapoor@crimson.ua.edu; monica.kapoor@netl.doe.gov

Tyler Kaub - tmkaub@crimson.ua.edu

Kristopher A Darling - kristopher.a.darling.civ@mail.mil

Brad L Boyce - blboyce@sandia.gov

Gregory B Thompson - gthompson@eng.ua.edu

C 2016. This manuscript version is made available under the Elsevier user license http://www.elsevier.com/open-access/userlicense/1.0/ 


\section{Abstract}

$\mathrm{Nb}$ solute behavior and its effect on grain size stabilization in $\mathrm{Cu}-\mathrm{Nb}$ alloys was studied using a combination of Vickers hardness testing, x-ray diffraction measurements, transmission electron microscopy and atom probe tomography (APT). Cu-Nb alloys with concentrations in the range from 1 to 10 at. \% Nb were studied after annealing at $400^{\circ} \mathrm{C}$ and $800^{\circ} \mathrm{C}$. The grain growth resistance at both temperatures increased with an increase in $\mathrm{Nb}$ solute content. For instance, after annealing at $800^{\circ} \mathrm{C}(0.74 \mathrm{Tm}), \mathrm{Cu}-1 \mathrm{Nb}, \mathrm{Cu}-5 \mathrm{Nb}$ and $\mathrm{Cu}-10 \mathrm{Nb}$ have a grain size that is $\sim 8, \sim 14$ and $\sim 14$ times respectively smaller than that of unalloyed $\mathrm{Cu}$. This resistance is attributed to the formation of Nb-oxide-based clusters, elemental $\mathrm{Nb}$ segregation zones and large elemental ( $\mathrm{Nb}$ )-based precipitates as observed by APT. The $\mathrm{Nb}$-oxide-based clusters are the precursors of phase separation and form due to a reaction with oxygen, which is a contaminant from the milling process. Once the oxygen is consumed, the process continues and the grain boundaries accumulate more solute and begin to thicken into elemental $\mathrm{Nb}$ segregation zones. Eventually, $\mathrm{Nb}$ solute phase separates and forms $\mathrm{Nb}$-based precipitates. After annealing at $400^{\circ} \mathrm{C}$ and $800^{\circ} \mathrm{C}$, Cu-5 $\mathrm{Nb}$ has a hardness which is approximately 2.5 times and 3 times respectively that of the hardness of unalloyed $\mathrm{Cu}$ after an equivalent anneal. This increase has been attributed to Hall-Petch strengthening and precipitation strengthening. 


\section{Introduction}

As the grain size of a material decreases, its properties can also change in response to the smaller length scale. A classic example of this is Hall-Petch strengthening which predicts that yield strength increases proportional to the inverse square root of the grain size [1-3]. Consequently, nanocrystalline materials have received considerable attention because of their size-dependent mechanical, electrical, creep resistance and other related properties [4-12]. However, at these smaller length scales, there is substantial excess free energy in the system because of the interfacial energy associated with the high grain boundary density. At high temperatures, such a system is diffusively able to reduce this driving force by grain growth, with the subsequent loss of the desired properties associated with nanocrystalline grain size [13]. Consequently, the ability to stabilize nanocrystalline materials against such grain growth has been an area of active research.

Nanocrystalline stability can generally be achieved via kinetic stabilization or thermodynamic stabilization [13-15]. Kinetic stabilization refers to pinning the grain boundaries through some type of secondary phase or solute to impede boundary motion [16]. This type of grain size control is often lost at high temperatures when the boundaries are energetically able to overcome the pinning barrier [13]. Thermodynamic stabilization refers to reducing the driving force for grain growth by allowing a solute to segregate to the grain boundaries and thereby lowering the excess free energy of grain boundaries. This type of grain size control has been predicted to have a low dependence on temperature and therefore can result in stabilization at elevated temperatures [10, 13].

This concept of solute segregation to grain boundaries for thermodynamic nanocrystalline grain stabilization was developed about 20 years ago and has been an area of extensive studies [7, 8, 10,14, 15, 17-27]. A classic prediction of thermodynamic stabilization is a decrease in grain size accompanied by increasing solute content $[20,24,26]$. For instance, in Fe-Zr alloys, on 
increasing the $\mathrm{Zr}$ solute content from 0.3 at. $\%$ to 4 at. $\%$ at $700^{\circ} \mathrm{C}$, the stabilized grain size decreased from $\sim 40 \mathrm{~nm}$ to $\sim 15-20 \mathrm{~nm}$ [24]. This solute segregates to the grain boundary and is accommodated in the grain boundary region resulting in a distinct equilibrium grain size for a given solute content at a given temperature. Eventually, the grain boundary reaches a saturation with respect to the amount of solute it can accommodate after which the solute is incorporated within the grain interior or forms precipitates [20]. Such a precipitation event is considered disadvantageous to grain size stabilization because precipitates provide only kinetic stabilization via Zener pinning. Consequently, thermodynamic stabilization and nanocrystalline grain size stability can be lost with a subsequent grain growth. For example, in the same $\mathrm{Fe}-\mathrm{Zr}$ alloys discussed above, upon increasing the $\mathrm{Zr}$ content to 10 at. \%, second phase precipitation occurred and the grain size did indeed increase [24].

On the other hand, recent studies on mechanically alloyed $\mathrm{Cu}$-Ta and W$\mathrm{Cr}$ have each reported a stable nanocrystalline grain structure despite the precipitation of a second phase $[10,23,28]$. In mechanical alloying, the nanocrystalline structure is achieved by ball milling constituent powders together which forces the solute atoms into solid solution [7, 10, 28]. Upon annealing, this solid solution is predicted to decompose and the resulting solute will segregate to the grain boundaries resulting in lowering the grain boundary free energy [10, 28]. In immiscible systems, such as $\mathrm{Cu}-\mathrm{Ta}$, the solute will initially segregate to the grain boundaries and subsequently form atom clusters (few 10 s of atoms) at grain boundaries and in the lattice. This will be followed by second phase precipitation thereby pinning the microstructure and resulting in kinetic and thermodynamic stabilization [10]. Molecular dynamics simulations on $\mathrm{Cu}-\mathrm{Ta}$ system have predicted Ta cluster formation along the grain boundary, which results in grain boundary pinning and thereby nanocrystalline grain size stabilization [25]. This nanocrystalline grain size stabilization with Ta clusters is concomitant with precipitation of larger Ta precipitates (approximately $100 \mathrm{~nm}$ ) which have been shown to stabilize the nanocrystalline structure up to temperatures as high as $0.97 \mathrm{~T}_{\mathrm{m}}$ [10]. Similarly, in mechanically alloyed $\mathrm{W}-\mathrm{Ti}$, the 
excellent grain coarsening resistance was attributed to approximately $1 \mathrm{~nm}$ thick segregation zones of Ti-rich regions around the grain boundary regions [22]. These segregation zones were observed in the microstructure despite the equilibrium phase diagram predicting a solid solution. Since these segregation zones did not result in distinct reflections in the diffraction patterns, it was inferred that they did not possess a distinct crystal structure, unlike precipitates. All these studies demonstrate that stabilization mechanisms at the nanoscale can be complex and may differ from the dominant mechanisms in coarse-grained systems [10, 22, 23, 28].

Another potentially promising immiscible system with similar segregation properties to $\mathrm{Cu}-\mathrm{Ta}$ is the $\mathrm{Cu}-\mathrm{Nb}$ system. Cu-Nb system is not among any of the binary pairs in the thermodynamic stability maps predicting stability against grain growth, i.e. it is not known how the system will behave [29]. Segregation enthalpy (a solute's tendency to segregate to the grain boundaries) of both of these systems is quite similar and is in the range of 0 to $-25 \mathrm{KJ} / \mathrm{mol}$ [29]. Their equilibrium phase diagrams do not show any regions of solubility indicating that precipitation of a second phase would be expected. Furthermore, Cu-Nb alloys have also received considerable attention as being one of the strongest $\mathrm{Cu}$-alloy systems [30] with an excellent combination of ductility and mechanical strength coupled with high electrical flux and radiation tolerance [4, 31, 32]. Even more appealing would be Nb's cost, which is approximately 25 times less expensive than Ta.

Though no dedicated experimental/computational study to address nanocrystalline stability in $\mathrm{Cu}-\mathrm{Nb}$ has been performed, there is circumstantial evidence in the literature to suggest that $\mathrm{Cu}-\mathrm{Nb}$ may possess stability attributes that have previously been observed in $\mathrm{Cu}-\mathrm{Ta}$. In these prior $\mathrm{Cu}-\mathrm{Nb}$ studies [4, $31,33,34]$, the $\mathrm{Cu}-\mathrm{Nb}$ was mechanically alloyed resulting in nanocrystalline grain sizes with a decrease in grain size with increasing solute content or increase in milling time (which is equivalent to 'forcing' more solute into the matrix phase) [34]. At high solute contents and/or increased annealing time, transmission and scanning electron microscopy revealed the presence of $\mathrm{Nb}$-rich precipitates 
within the microstructure $[4,31,33,34]$. Though some of these studies followed the microstructure evolution as a function of processing conditions (composition and temperature), none of them explicitly addressed how the solute behavior evolves or provides nanocrystalline stabilization. Rather, those former works primarily addressed optimizing the electrical and mechanical properties of $\mathrm{Cu}-\mathrm{Nb}$.

In this study, pure $\mathrm{Cu}$ and $\mathrm{Cu}-\mathrm{Nb}$ alloys with concentrations from 1 to 10 at. $\% \mathrm{Nb}$ were mechanically alloyed and annealed at $400^{\circ} \mathrm{C}$ and $800^{\circ} \mathrm{C}$. The aim was to explore the solute behavior and track its influence on grain size stabilization and corresponding mechanical properties, using a combination of Vickers hardness, $x$-ray diffraction (XRD) measurements, transmission electron microscopy (TEM) and atom probe tomography (APT). An advantage of using APT is its high chemical and spatial sensitivity which can elucidate the nuances of the solute behavior, particularly at low solute concentrations, which cannot be captured by other microscopy techniques $[9,35]$. This is especially important in light of the hypothesis that $\mathrm{Nb}$ solute leads to stabilization of the alloys; low solute concentrations should capture the initial stages of the stabilization mechanism.

\section{Experimental Procedures}

Hardened steel vials and $440 \mathrm{C}$ stainless steel balls were used for mechanically alloying $\mathrm{Cu}$ and $\mathrm{Nb}$ powders ( -325 mesh, 99.95 to $98.5 \%$ purity) in a Spex 8000 shaker mill. A ball-to-powder ratio of 5:1 with a powder charge of $10 \mathrm{~g}$ was used. Vials were sealed in an argon atmosphere glove box with less than 1ppm oxygen concentration prior to milling. Mechanical alloying was performed at liquid nitrogen temperatures for 4 hours and resulted in unagglomerated powders with a particle size range of $20-100 \mu \mathrm{m}$. 3mm preform tablets were made by uniaxially pressing the as-milled powder in a $3 \mathrm{~mm}$ diameter tungsten carbide die at $3.5 \mathrm{GPa}$. These $3 \mathrm{~mm}$ coupons were subsequently annealed for one hour at $400^{\circ} \mathrm{C}$ and $800^{\circ} \mathrm{C}$ under argon $3 \% \mathrm{H}_{2}$ gas. 
For annealing, these $3 \mathrm{~mm}$ coupons were wrapped in Ta foil and placed in a quartz tube (open at one end) and then loaded into the tube furnace. The tube furnace was heated to the desired temperature and at the same time the quartz tube was placed under roughing vacuum and back filled with the forming gas, argon $3 \% \mathrm{H}_{2}$ (this procedure was repeated three times). For the last refill, the quartz tube was over-pressurized to approximately $1 \mathrm{psi}$ and the pressure held constant. Once the tube furnace was at temperature, the quartz tube was rolled into the tube furnace and the sample temperature continuously monitored via an internal thermocouple. Once the samples reached the appropriate temperature, the time for the 1 hour anneal was started. After 1 hour at temperature, the tube furnace was pulled off the quartz tube and the sample cooled down to room temperature under the forming gas. The samples were then extracted from the quartz tube by bleeding off the overpressure and opening it to atmosphere.

The following four alloy compositions were prepared using ball-milling and compacted into $3 \mathrm{~mm}$ coupons: unalloyed $\mathrm{Cu}$ (control), $\mathrm{Cu}-1 \mathrm{Nb}, \mathrm{Cu}-5 \mathrm{Nb}$ and $\mathrm{Cu}-$ $10 \mathrm{Nb}$ (at. \%). The nomenclature used in this paper reports the solute composition with the annealing temperature. Therefore, $\mathrm{Cu}-1 \mathrm{Nb} / 400^{\circ} \mathrm{C}$ means the alloy $\mathrm{Cu}-1 \mathrm{Nb}$ was annealed at $400^{\circ} \mathrm{C}$ for an hour. All the composition units are in at. \% throughout the manuscript, and all annealing times were 1 hour. The details are provided in Table1.

Although these materials were processed under flowing argon, oxygen, nitrogen, iron and carbon were found in the samples and these are generally present in ball milled materials as contaminants [10, 36]. Such contamination also represents some of the challenges in differentiating the effect of thermodynamic stabilization from kinetic stabilization on grain size. In this study, the amount of oxygen was found to be less than 1.5 at. \% and that of nitrogen was $<0.6$ at. \%. Between $\mathrm{Nb}$ and $\mathrm{Cu}, \mathrm{Nb}$ forms the more stable oxide and nitride $[37,38]$ and therefore is expected to react with oxygren or nitrogen preferentially. Most of the recent work in nanocrystalline stability has not explicitly addressed how the intrinsic contamination from the processing of the materials may effect stabilization. This could be due to the limited mass 
sensitivity, chemical and spatial resolution of the techniques used in prior studies compared to that of APT. Regardless, it seems very probable that any non-noble nanocrystalline alloy produced by ball milling, melt spinning, electro-deposition or physical vapor deposition would be susceptible to these impurities and their effect on stabilization [39, 40]. The implications of these reactions will be discussed in section 4.1.

Vickers hardness testing was performed using a Beuhler Vicker's hardness tester under a $50 \mathrm{~g}$ load for $15 \mathrm{~s}$. The hardness reported for each sample is an average of ten measured hardness indents. Care was taken to ensure that each indent was made in an area free of pores and that each indent had a uniform shape.

XRD of Cu-Nb alloys was performed using a Bruker D8 x-ray diffractometer with Co-Ka as the radiation source and that of unalloyed $\mathrm{Cu}$ was performed using a PANalytical X'Pert powder system with $\mathrm{Cu}-\mathrm{Ka}$ as the radiation source. The scans were conducted in the range of $2 \theta=30^{\circ}-105^{\circ}$ and the (111), (200), (220) peaks used to calculate the average grain size with the Scherrer equation [41], as has been used in many previous studies on nanocrystalline grain stabilization $[10,42]$. Full-width at half-maximum of these peaks was identified in Origin Pro software 8.1 using the multi-peak fit function. The calculated grain sizes (in $\mathrm{nm}$ ) are listed in Table 2 (a).

To confirm that the grain size estimates from Scherrer analysis of XRD measurements were accurate, precession electron diffraction (PED) and electron backscatter diffraction (EBSD) studies were performed for a few samples where the divergence in actual grain sizes was most likely to occur. For PED, the TEM studies were performed using a $200 \mathrm{keV}$ field emission FEI Tecnai TEM. The TEM specimens were prepared in a FEI Quanta 200 3D Dual Beam ${ }^{\mathrm{TM}}$ using a lift-out and thinning procedure with $0.5 \mathrm{nA}$ and $0.3 \mathrm{nA}$ current respectively at 30 $\mathrm{keV}$ beam energy. A low-keV clean-up step was performed using $5 \mathrm{keV}$ beam energy at $70 \mathrm{pA}$ current followed by a 15 minute final polish by argon ion milling using Gatan 691 precision ion polishing system. Automated crystal orientation mapping via PED was performed using the NanoMegas ASTAR® system, which 
allows mapping with spatial resolution down to approximately $2 \mathrm{~nm}$. Crystal orientation maps were collected over a $1 \mu \mathrm{m} \times 1 \mu \mathrm{m}$ region using a step size of $4 \mathrm{~nm}$ and a precession angle of $0.3^{\circ}$. The diffraction pattern indexing was performed using the ASTAR matching software with copper as the template. The orientation data was then exported to OIM Analysis 7 software, where it was optimized using grain dilation, neighbor confidence interval correlation and automated crystallography for TEM corrections. EBSD was performed using an EDAX EBSD platform on a Tescan Lyra SEM at an accelerating voltage of 20 $\mathrm{KeV}$. The samples were prepared by polishing to a $3 \mu \mathrm{m}$ surface finish, followed by vibratory polishing for $2 \mathrm{hrs}$ using an aqueous $0.05 \mu \mathrm{m}$ silica slurry. The calculated grain sizes (in $\mathrm{nm}$ ) are listed in Table 2 (b).

APT was used to identify solute segregation using a Cameca local electrode atom probe $(\mathrm{LEAP} \cap) 3000 \mathrm{XSi}$. The atom probe tips were fabricated in a FEI Quanta 200 3D Dual Beam ${ }^{\mathrm{TM}}$ using a lift-out and annular-milling sharpening procedure with $0.5 \mathrm{nA}$ and $0.3 \mathrm{nA}$ current respectively at $30 \mathrm{keV}$ beam energy. A low energy clean-up step using $70 \mathrm{pA}$ current and $5 \mathrm{keV}$ beam energy was performed for 2 minutes to reduce the Ga ion implantation on the surface. APT experimental run parameters were optimized by a set of careful experiments. Laser pulsing, using a laser with $\lambda=532 \mathrm{~nm}$, was chosen because of the high fracture rate of high $\mathrm{Nb}$ solute samples under voltage pulsing. The laser pulse repetition rate was $200 \mathrm{kHz}$, pulse energy - $0.3 \mathrm{~nJ} /$ pulse, evaporation rate - $0.5 \%$ and the base temperature $-233^{\circ} \mathrm{C}(40 \mathrm{~K})$ for all measurements. The atom probe data was analyzed using Image Visualization and Analysis Software (IVAS ${ }^{\mathrm{TM}}$ ) 3.6.6 package. The reconstruction was performed using voltage method and the mass spectrum bin size was kept constant at 0.01 Dalton. Typically, three tips were studied for each composition at each temperature.

Generally, grain boundaries in APT reconstructions have been inferred by discernible segregation and applying computational geometry techniques to the reconstructions $[43,44]$. These techniques were applied to our data but failed to identify grain boundaries with density variations even when segregation was visually obvious. This difficulty is likely attributed to the small grain sizes, on the 
order of $10 \mathrm{~nm}$, and the presence of $\mathrm{Nb}$ clusters at the grain boundaries. Moreover, these procedures were developed to identify a uniformly distributed solute as is expected in most cases of interfacial segregation. In case of no visually obvious segregation, density fluctuations in the vicinity of the grain boundary regions have been used to identify these regions [45]. In this study, application of 2D chemical density maps to the reconstructions revealed an obvious density difference coinciding with the location of the segregation/solute clusters and was therefore chosen as one of the primary methods for data analysis. These chemical density maps used in conjunction with experimentally calculated grain sizes from XRD and TEM were then used to infer the presence of a grain boundary in the reconstruction.

\section{Results}

\subsection{Grain size}

Fig. 1(a) shows the XRD results of the (111) peaks of non-annealed/as-milled $\mathrm{Cu}$, as-milled $\mathrm{Cu}-1 \mathrm{Nb}$, as-milled $\mathrm{Cu}-5 \mathrm{Nb}$ and as-milled $\mathrm{Cu}-10 \mathrm{Nb}$. Since $\mathrm{Cu}$ and $\mathrm{Cu}-\mathrm{Nb}$ alloys were performed on diffractometers with different radiation sources, the results are normalized for comparison and $x$-axis is presented as the $d$ spacing. The as-milled $\mathrm{Cu}$ peak is thinnest and as the amount of $\mathrm{Nb}$ was increased, the peaks shift to larger d-spacing values indicating an increase or expansion of the crystalline lattice caused by the incorporation of $\mathrm{Nb}$ into $\mathrm{Cu}$ matrix as a solid solution. Furthermore, as more $\mathrm{Nb}$ was added, the peaks broadened suggesting a refinement of grain size and/or an increase in the inhomogeneous microstrain. Upon annealing, the (111) peak of $\mathrm{Cu}-5 \mathrm{Nb} / 400^{\circ} \mathrm{C}$ and $\mathrm{Cu}-5 \mathrm{Nb} / 800^{\circ} \mathrm{C}$ shifted to higher angles, indicating that the solute was diffusing out of the lattice and the lattice was contracting, Fig. 1(b).

Figure 2 (a) shows the EBSD map of unalloyed Cu, and Figure 2 (b) and (c) show PED scans of the $\mathrm{Cu}-1 \mathrm{Nb}$, and $\mathrm{Cu}-10 \mathrm{Nb}$ annealed at $800^{\circ} \mathrm{C}$, which represent the extreme conditions. The bottom row of each image shows the respective grain size distributions. As expected, the average grain size decreased with an increase in solute content - from $566 \mathrm{~nm} \pm 778$ for unalloyed 
$\mathrm{Cu}$ to $21.5 \mathrm{~nm} \pm 20.8$ for $\mathrm{Cu}-1 \mathrm{Nb} / 800^{\circ} \mathrm{C}$ to $19.3 \mathrm{~nm} \pm 14.3$ for $\mathrm{Cu}-10 \mathrm{Nb} / 800^{\circ} \mathrm{C}$. Grain size distribution of unalloyed Cu shows a wide grain size distribution with a few grains even in the 10-20 $\mu \mathrm{m}$ size range. In fcc metals, such an abnormal grain growth has been related to the fraction of certain types of coincident site lattice grain boundaries [46]. Even though the average grain size of $\mathrm{Cu}$ $1 \mathrm{Nb} / 800^{\circ} \mathrm{C}$ and $\mathrm{Cu}-10 \mathrm{Nb} / 800^{\circ} \mathrm{C}$ is quite close, it is obvious from the Fig. 2 (b and c) that the $\mathrm{Cu}-1 \mathrm{Nb} / 800^{\circ} \mathrm{C}$ shows quite a few grains which are larger. This suggests that the limited amount of 1 at. \% Nb solute impacts the grain growth depending on the grain boundary type, as has been experimentally observed in $n c \mathrm{Fe}-\mathrm{Cr}$ system [47]. It is worth noting that the grain sizes of the Cu-Nb alloys obtained from EBSD and PED were in good agreement with those obtained from XRD.

A combination of EBSD, PED and XRD results was used to analyze the impact of temperature and $\mathrm{Nb}$ solute content on the $\mathrm{Cu}-\mathrm{Nb}$ alloy grain size. For this analysis, grain sizes obtained from XRD results were used for $\mathrm{Cu}-\mathrm{Nb}$ alloys and those obtained from EBSD results were used for unalloyed $\mathrm{Cu}$. To accurately quantify the influence of temperature and $\mathrm{Nb}$ composition on the grain size relative to that of unalloyed $\mathrm{Cu}$, a normalized grain size was calculated for each alloy at each temperature as it provided a quick reference to the degree of grain growth in each alloy. For instance, the grain size of unalloyed $\mathrm{Cu}$ and $\mathrm{Cu}$ $1 \mathrm{Nb}$ after annealing at $800^{\circ} \mathrm{C}$ is $\sim 566 \mathrm{~nm}$ and $\sim 72 \mathrm{~nm}$ respectively and the relative grain size is 7.8 ; i.e. the unalloyed $\mathrm{Cu}$ grains are $7.8 \mathrm{X}$ larger. Hence, the higher the normalized grain size, the smaller the alloy grain size that is stabilized at a particular solute content. For all the relative grain sizes, the unalloyed $\mathrm{Cu}$ was compared to the $\mathrm{Cu}-\mathrm{Nb}$ for the equivalent annealing condition.

Fig. 3 plots the normalized grain size as a function of composition and shows the effect of annealing temperature. Consistent with the EBSD and PED scans of Fig. 2, the stabilized grain size decreased or the grain growth resistance increased as the amount of $\mathrm{Nb}$ was increased. For instance, the grain size of $\mathrm{Cu}-1 \mathrm{Nb} / 400^{\circ} \mathrm{C}, \mathrm{Cu}-5 \mathrm{Nb} / 400^{\circ} \mathrm{C}$ and $\mathrm{Cu}-10 \mathrm{Nb} / 400^{\circ} \mathrm{C}$ is $\sim 6.5, \sim 19.4$, and $\sim 29.5$ times respectively smaller than that of unalloyed $\mathrm{Cu}$ annealed at $400^{\circ} \mathrm{C}$. 
Similarly, the normalized grain size of $\mathrm{Cu}-1 \mathrm{Nb} / 800^{\circ} \mathrm{C}, \mathrm{Cu}-5 \mathrm{Nb} / 800^{\circ} \mathrm{C}$ and $\mathrm{Cu}-$ $10 \mathrm{Nb} / 800^{\circ} \mathrm{C}$ is $\sim 7.8, \sim 13.8$ and $\sim 14.1$ times smaller than that of unalloyed $\mathrm{Cu}$ annealed at $800^{\circ} \mathrm{C}$. Details of relative grain size are listed in Table 2(c). To highlight the stabilization, consider that $800^{\circ} \mathrm{C}$ is $0.74 \mathrm{~T}_{\mathrm{m}}$ of $\mathrm{Cu}$ and the stabilized grain size on alloying with $5 \mathrm{Nb}$ and $10 \mathrm{Nb}$ is approximately an order of magnitude smaller than that of unalloyed $\mathrm{Cu}$. Second, the normalized grain sizes that were stabilized in $\mathrm{Cu}-5 \mathrm{Nb} / 800^{\circ} \mathrm{C}$ and $\mathrm{Cu}-10 \mathrm{Nb} / 800^{\circ} \mathrm{C}-13.8$ and 14.1 respectively are nearly equivalent. Liu et al. [20] have predicted that as grain boundary saturation is reached, further increases in solute would not affect the grain growth.

\subsection{Vickers Hardness}

To assess the degree of strengthening due to grain size refinement in these alloys, Vickers hardness testing was performed. According to the Tabor relationship, the flow stress of a material is approximately one-third of the Vickers hardness [48]. Using this rule of thumb, measured Vickers hardness has been converted into flow stress and plotted alongside calculated Hall-Petch strengthening from grain size [49] as a function of $\mathrm{Nb}$ composition. The HallPetch strengthening is calculated using $-\sigma=\sigma_{0}+k_{y} / \sqrt{d}$ where $\sigma_{0}=25 \mathrm{MPa}, \mathrm{k}_{\mathrm{y}}=$ $0.137 \mathrm{MPa} \sqrt{\mathrm{m}}$, and $\mathrm{d}=$ grain size [50].

Fig. 4 (a) and (b) show the results for $\mathrm{Cu}-\mathrm{Nb} / 400^{\circ} \mathrm{C}$ and $\mathrm{Cu}-\mathrm{Nb} / 800^{\circ} \mathrm{C}$ with the empty symbols representing the calculated Hall-Petch strengthening and the filled symbols representing the measured values. The main finding is that after annealing at $400^{\circ} \mathrm{C}$, unalloyed $\mathrm{Cu}$ (data points on y-axis) has a strength of 0.67 $\mathrm{GPa}$ but $\mathrm{Cu}-5 \mathrm{Nb}$ has a strength of $1.62 \mathrm{GPa}$, an increase of approximately 2.5 times, consistent with the results of other studies [4,51,52]. At this temperature, grain size strengthening (represented by empty circles) contributes approximately $75-90 \%$ of the observed strength (represented by filled circles).

After annealing at $800^{\circ} \mathrm{C}$, unalloyed $\mathrm{Cu}$ has a strength of $0.36 \mathrm{GPa}$ whereas $\mathrm{Cu}-5 \mathrm{Nb}$ has a strength of $1.07 \mathrm{GPa}$, an increase of approximately 3 times. At this temperature for $\mathrm{Cu}-5 \mathrm{Nb}$, grain size strengthening (represented by empty squares) contribute approximately $65 \%$ to the observed strength (represented by 
filled squares). These results indicate that other strengthening mechanisms, in addition to grain size strengthening, are operative at various points in this composition and temperature space [7].

\subsection{Microstructure evolution}

APT was performed on all samples to understand the solute behavior as a function of composition and temperature in the $\mathrm{Cu}-\mathrm{Nb}$ alloys. To orient the readers to the collective context of the results, a few highlights of the results have been listed before presenting the details associated with these results. As will be shown, the $\mathrm{Cu}-1 \mathrm{Nb}$ alloy at both $400^{\circ} \mathrm{C}$ and $800^{\circ} \mathrm{C}$ reacted with the impurities forming solute-oxide and -nitride clusters, where a cluster refers to a very early stage of phase separation (similar to Guinier-Preston (GP) zones). Quantitatively a cluster represents a distinct group of atoms which are enriched with solute, but the solute is still the minor constituent $(<50$ at. \%).

$\mathrm{Cu}-5 \mathrm{Nb} / 400^{\circ} \mathrm{C}$ has elemental $\mathrm{Nb}$ segregation zones and $\mathrm{Nb}$-oxide-based clusters and $\mathrm{Cu}-10 \mathrm{Nb} / 400^{\circ} \mathrm{C}$ has these same features plus large elemental $(\mathrm{Nb})$ based precipitates. These 'segregation zones' refer to inhomogenously distributed solute atoms, similar to the segregation zones observed by Chookajorn et al. [22] and by Clark et al. [53]. Upon annealing at $800^{\circ} \mathrm{C}$, the $\mathrm{Cu}$ $5 \mathrm{Nb}$ and $\mathrm{Cu}-10 \mathrm{Nb}$ alloys also had $\mathrm{Nb}$-oxide-based clusters in addition to the second-phase precipitation of $\mathrm{Nb}$ solute. Quantitatively, these precipitates are defined as having $>50$ at. \% solute atoms and represent advanced stages of phase separation.

\subsection{1. $400^{\circ} \mathrm{C}$}

An atom map of $\left(\mathrm{Cu}+\mathrm{NbO}+\mathrm{NbO}_{2}\right)$ in $\mathrm{Cu}-1 \mathrm{Nb} / 400^{\circ} \mathrm{C}$, Fig. 5 (a) revealed the presence of numerous clusters. As discussed, the word 'clusters' is used to describe solute-rich regions with $<50$ at. \% solute atoms. The composition of these clusters, obtained from a proximity histogram [54] of 6 at. \% $\left(\mathrm{NbO}+\mathrm{NbO}_{2}\right)$

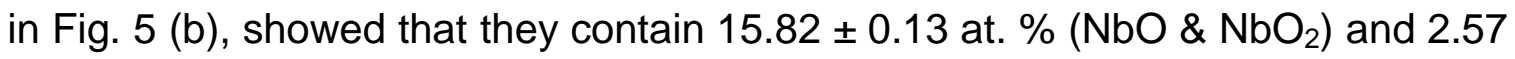
\pm 0.08 at. $\% \mathrm{Fe}$. The much higher oxide content confirmed that these clusters are $\mathrm{Nb}$-oxide-based. These clusters also contain 1 at. \% $(\mathrm{NbC}+\mathrm{NbN})$, inset in 
Fig. 5(b). As discussed in Section 2, the presence of oxygen, nitrogen, iron and carbon is believed to be a result of contamination from the steel vials/balls that were used in mechanical alloying and the gaseous atmosphere contained within the vials $[10,36]$.

Atom probe reconstructions do not provide 100\% lattice rectification and therefore microstructural features, such as grain boundaries or dislocations, are not directly observed. However, their presence can be inferred based on either a segregating species/precipitates occurring along a three- or two- dimensional feature respectively, or on chemical density differences. Therefore, in addition to using 6 at. $\%\left(\mathrm{NbO}+\mathrm{NbO}_{2}\right)$ isoconcentration surfaces to delineate the spatial distribution of these $\mathrm{Nb}$-oxide-based clusters, density maps of differences of $\left(\mathrm{Fe}+\mathrm{NbO}+\mathrm{NbO}_{2}\right)$ were also used, Fig. 5(c). Regions of high-density clusters in the analyzed volume are labeled (with an arrow) and the following observations were made: First, the clusters appeared to be grouped on 2D planes which are angled in different directions, and would be consistent with the planar orientation of a grain boundary. Linking this observation with the knowledge from previous experimental work [10] that coarser solute precipitates are found along grain boundaries, it is reasonable to infer that these high-density cluster groups are present along a grain boundary. Second, the size and number of these planar cluster groups were consistent with the number of grain boundaries that would be present in the atom probe reconstructed volume. For example, in Fig. 5(c), three regions of high-density cluster groups are present in the $60 \mathrm{~nm} \times 60 \mathrm{~nm} \times 90 \mathrm{~nm}$ atom map volume. This would be a reasonable number of grain boundaries for an average grain size of $25 \mathrm{~nm}$, Table 2 (a). Third, the regions between these areas of high-density clusters are denuded of enriched clusters, Fig. 5 (c), suggesting that these are interior regions of the grains. Finally, the above inferences are consistent with expectations because at this low (1 at. \%) solute content, the grain boundary has not yet reached the solute saturation point and can accommodate more solute. Thus, an appreciable amount of solute would not be expected within the grain interior [20]. 
Additionally, a negligible amount (approximately 0.03 at. \%) of elemental $\mathrm{Nb}$ was observed in the time-of-flight mass spectrum in this $\mathrm{Cu}-1 \mathrm{Nb} / 400^{\circ} \mathrm{C}$ alloy. This observation indicates that most of the elemental $\mathrm{Nb}$ has reacted with the impurities and formed the clusters at the grain boundaries. The formation of such $\mathrm{Nb}$-oxide-based clusters was first hypothesized by Botchorva et al. [34] and this is the first experimental observation of such clusters. Clark et al. [53] have also noted the presence of analogous solute-oxide (MgO-type) clusters in Fe-10 at. \% $\mathrm{Mg}$ and have proposed that these clusters could be a source of grain size stability.

Next, the $\mathrm{Cu}-5 \mathrm{Nb} / 400^{\circ} \mathrm{C}$ microstructure is addressed as this alloy resulted in highest strength, 1.6 GPa. Fig. 6 shows projections of $15 \mathrm{~nm}$ thick atom maps of (a) $\mathrm{Cu}, \mathrm{Nb}$, and $\mathrm{Fe}$ and (b) maps of $(\mathrm{Cu}+\mathrm{Fe}),(\mathrm{Nb}+\mathrm{Fe})$ and $(\mathrm{NbN}+\mathrm{NbO})$ in $\mathrm{Cu}-$ $5 \mathrm{Nb} / 400^{\circ} \mathrm{C}$. Fig. 6 (c) is a $1 \mathrm{D}$ profile with the cylinder showing the volume through which it is obtained. The composition profile reveals the presence of regions enriched with $24.26 \pm 3.68 \mathrm{Nb}, 36.76 \pm 4.13 \mathrm{Fe}, 19.11 \pm 3.37 \mathrm{NbO}$ and $5.88 \pm 2.02 \mathrm{NbN}$ (at. \%) with a spatial periodicity of $\sim 15 \mathrm{~nm}$. This periodicity appears to be consistent with the grain size range estimated by XRD $(8.4 \mathrm{~nm})$ and PED (14 nm). The minor grain size difference between XRD, PED and APT could be attributed to the fact that grain size from Scherrer analysis (XRD) is an average of grain sizes along three orientations (the largest grain size being 11.5 $\mathrm{nm}$ ) as well as XRD and PED being stereological analyses techniques. Regardless, the important observation is that with 5 at. \% solute content, elemental $\mathrm{Nb}$ is observed to be enriched at grain boundaries in addition to $\mathrm{Nb}$ oxide-based clusters.

To compare the details of this enriched zone to that of the low solute $\mathrm{Cu}$ $1 \mathrm{Nb} / 400^{\circ} \mathrm{C}, 8$ at. $\% \mathrm{NbO}$ isoconcentration surface was created and its proxigram, Fig. 6 (d), shows their composition to be $16.83 \pm 0.35 \mathrm{Nb}, 17.50 \pm 0.36 \mathrm{Fe}, 42.67$ $\pm 0.46 \mathrm{NbO}, 3.29 \pm 0.17 \mathrm{NbN}$ (at. \%). A few details that can be gleaned from the proxigram are that the peaks in composition of elemental $\mathrm{Nb}$ and $\mathrm{Fe}$ (labeled with an arrow), at $0.4 \mathrm{~nm}$ on the $\mathrm{x}$-axis, are not co-located with the $\mathrm{NbO}$ peak. This indicates that the elemental $(\mathrm{Nb}+\mathrm{Fe})$ enrichment and $\mathrm{Nb}$-oxide-based clusters 
are adjacent to each other and are distinct features. Second, there is minimal (0.04 at. \%) elemental oxygen within the isoconcentration surface (not shown in the image). This indicates that initially when $\mathrm{Nb}$ began to segregate, it reacted with oxygen. Once all oxygen was consumed, the remaining $\mathrm{Nb}$ was present as a solute in the vicinity and explains the adjacent peaks observed in the proxigram. The above described pathway resulted in the formation of $\mathrm{Nb}$-oxidebased clusters followed by the remaining $(\mathrm{Nb}+\mathrm{Fe})$ solute present as a segregation zone in the vicinity.

Next, the effect of increasing the solute content to 10 at. \% $\mathrm{Nb}$ is reported. Fig. 7(a), projections of atom maps of $\mathrm{Cu}, \mathrm{Fe}, \mathrm{Nb},(\mathrm{NbO}+\mathrm{NbN})$, and a 2D density map of $\mathrm{Nb}$ in $\mathrm{Cu}-10 \mathrm{Nb} / 400^{\circ} \mathrm{C}$, shows large $\mathrm{Nb}$-rich precipitates and a region of elemental $(\mathrm{Nb}+\mathrm{Fe})$ and $(\mathrm{NbO}+\mathrm{NbN})$ enrichment. A 1D composition profile, Fig. 7 (b), was obtained through both the region of enrichment and Nb-rich precipitate with the cylinder marking the volume through which the composition profile was obtained.

The $(\mathrm{Nb}+\mathrm{Fe})$ segregation zone in this alloy contained $37.62 \pm 2.71 \mathrm{Fe}$, $23.51 \pm 2.37 \mathrm{Nb}$, and $11.20 \pm 1.76(\mathrm{NbO}+\mathrm{NbN})($ at. \%) clearly indicating that elemental $(\mathrm{Nb}+\mathrm{Fe})$ is present in the same neighborhood as $(\mathrm{NbO}+\mathrm{NbN})$. This proximity of $(\mathrm{NbO}+\mathrm{NbN})$ to elemental $(\mathrm{Nb}+\mathrm{Fe})$ solute is very similar to the phenomenon observed in low solute $\mathrm{Cu}-5 \mathrm{Nb} / 400^{\circ} \mathrm{C}$ and indicates that the pathway of segregation and cluster formation is similar. The Nb-rich precipitate is $\sim 12 \mathrm{~nm}$ (full-width at half-maximum of $\mathrm{Nb}$ concentration) and has $~ 74.60 \pm 3.22$ $\mathrm{Nb}$ and $\sim 10.89 \pm 2.31 \mathrm{NbO}$ (at. \%) and does not have any Fe (unlike the elemental segregation zone). This absence of Fe clearly indicates that this $\mathrm{Nb}$ rich precipitate is a separate entity from the $(\mathrm{Nb}+\mathrm{Fe})$ solute enrichment. Observing the details of peak location in the $1 \mathrm{D}$ profile, the peak in $\mathrm{NbO}$ composition is at $29 \mathrm{~nm}$ (labeled by an arrow) whereas the peak of $\mathrm{Nb}$ composition is at $31 \mathrm{~nm}$. This seems to suggest that $\mathrm{NbO}$ formed first with oxygen acting as the limiting agent. After the oxygen was consumed, the remaining $\mathrm{Nb}$ solute in this high-solute content $\mathrm{Cu}-10 \mathrm{Nb} / 400^{\circ} \mathrm{C}$ alloy formed a $\mathrm{Nb}$-rich precipitate. The above described pathway is similar to that in $\mathrm{Cu}$ - 
$5 \mathrm{Nb} / 400^{\circ} \mathrm{C}$, but in this case the phase separation of $\mathrm{Nb}$ solute is in an advanced stage probably due to the higher amount of solute. This presence of solute rich, elemental $\mathrm{Nb}$ precipitates at high solute content is consistent with other studies $[7,9]$.

\subsection{2. $800^{\circ} \mathrm{C}$}

Fig. 8 (a) is the atom map of $\left(\mathrm{Cu}+\mathrm{NbO}+\mathrm{NbO}_{2}+\mathrm{NbN}\right)$ in $\mathrm{Cu}-1 \mathrm{Nb} / 800^{\circ} \mathrm{C}$ and two distinct populations of $\mathrm{Nb}$-oxide-based and $\mathrm{NbN}$-based clusters were noted. Very little elemental $\mathrm{Nb}(0.08$ at. \%) was observed in this alloy. In this composite view, it was difficult to identify any spatial distribution patterns. However by viewing the Nb-oxide-based clusters separately, Fig. 8(b), their spatial distribution revealed two regions of high-density clusters in the vicinity of 3D features, marked by blue lines to guide the eye. The first set of high density clusters consist of $6 \mathrm{Nb}$-oxide-based precipitates, bottom left of Fig. 8 (b), and are located on a curved $3 \mathrm{D}$ region indicating that they are on a grain boundary. The second set of $\mathrm{Nb}$-oxide-based clusters were observed around the middle of the reconstruction, Fig. 8(b), and then down the angled plane (marked by a blue line) which is consistent with a grain boundary. Two regions of such high-density precipitates are present in the atom map of $60 \mathrm{~nm} \times 60 \mathrm{~nm} \times 60 \mathrm{~nm}$, which is a reasonable number of grain boundaries for a grain size of $72 \mathrm{~nm}$. Last, the regions on both sides of these areas of high-density precipitates do not show any similar clusters, suggesting (as above) that these are interior regions of the grain. Their proximity histogram, Fig. 8 (c), shows that they have $15.72 \pm 0.10$ at. \% $\left(\mathrm{NbO}_{2}+\mathrm{NbO}\right)$ and have less than 2 at. \% Fe. Observation of these similar clusters at 1 at. \% solute content, regardless of the annealing temperature, strongly indicates that the formation of $\mathrm{Nb}$-oxide-based clusters at grain boundaries is a common initial mechanism.

At the higher solute composition, $\mathrm{Cu}-5 \mathrm{Nb} / 800^{\circ} \mathrm{C}$, an advanced level of phase separation with two distinct phases are observed in Fig. $9(\mathrm{a})-1)(\mathrm{Nb}+\mathrm{Fe})$ precipitates delineated by green-colored 20 at. $\%(\mathrm{Nb}+\mathrm{Fe})$ isoconcentration surface, and 2) $\mathrm{Nb}$-oxide-based precipitates delineated by purple-colored 8 at. \% $\left(\mathrm{NbO}+\mathrm{NbO}_{2}\right)$ isoconcentration surface. The $\mathrm{Nb}$-oxide-based precipitates, Fig. 9 
(b), contain $15.31 \pm 0.55 \mathrm{NbO}, 41.02 \pm 0.74 \mathrm{NbO}_{2}, 17.74 \pm 0.58 \mathrm{Fe}, 7.44 \pm 0.40$ $\mathrm{Nb}$ (at. \%), and less than 3 at. \% $(\mathrm{NbN}+\mathrm{NbC})$. These Nb-oxide-based precipitates are more enriched ( 60 at. \% compared to $15-20$ at. \%) in $\mathrm{NbO}$ and $\mathrm{NbO}_{2}$ and are also larger ( $3.5 \mathrm{~nm}$ compared to 1-2 nm radius) compared to $\mathrm{Nb}$ oxide-based clusters in any other alloy discussed in this study.

The three larger $(\mathrm{Nb}+\mathrm{Fe})$ precipitates, Fig. 9 (c), comprise of $31.26 \pm 0.40$ $\mathrm{Nb}$ and $65.10 \pm 0.40 \mathrm{Fe}$ (at. \%). In the proxigram, there is a peak in $\mathrm{NbO}$ and $\mathrm{NbO}_{2}$ at $1 \mathrm{~nm}-2 \mathrm{~nm}$, near the interface (marked with an arrow). This indicates that some of $\mathrm{NbO}$ and $(\mathrm{Nb}+\mathrm{Fe})$ precipitates, labeled with an arrow in Fig. 9 (a), are forming adjacent to each other from the same solute reservoir. This phenomenon is similar to the observations in other high-solute alloys, Cu$5 \mathrm{Nb} / 400^{\circ} \mathrm{C}$ had elemental $(\mathrm{Nb}+\mathrm{Fe})$ solute adjacent to $\mathrm{Nb}$-oxide-based clusters and $\mathrm{Cu}-10 \mathrm{Nb} / 400^{\circ} \mathrm{C}$ had $\mathrm{Nb}$-oxide-based clusters adjacent to $\mathrm{Nb}$-rich precipitate, suggesting a common solute-content-dependent pathway. It is also interesting to note that this $(\mathrm{Nb}+\mathrm{Fe})$ precipitate is distinct from the $\mathrm{Nb}$-rich precipitate in $\mathrm{Cu}$ $10 \mathrm{Nb} / 400^{\circ} \mathrm{C}$ in that the latter did not have any $\mathrm{Fe}$ in it. The presence of these larger precipitates at this annealing temperature is consistent with previous studies on $\mathrm{Cu}-10 \mathrm{Nb}$ which showed the formation of $\sim 60 \mathrm{~nm} \mathrm{Nb}$-based precipitates on annealing at $600^{\circ} \mathrm{C}[4,31]$.

To emphasize the spatial distribution of each type of precipitate, Fig. 9 (d) and (e) show only the 8 at. $\%\left(\mathrm{NbO}+\mathrm{NbO}_{2}\right)$ and 20 at. \% $(\mathrm{Nb}+\mathrm{Fe})$ isoconcentration surfaces respectively. The $\mathrm{Nb}$-oxide-based precipitates are distributed on a 3D feature along the middle of the reconstruction, Fig. 9(d). Among the three $(\mathrm{Nb}+\mathrm{Fe})$ precipitates, two of the larger precipitates are also along this same 3D feature making it likely that both types of precipitates are forming on a grain boundary. Regardless of these details, this alloy shows the $\mathrm{Nb}$ solute to be in advanced stage of phase separation with the formation of $(\mathrm{Nb}+\mathrm{Fe})$ precipitates and the $\mathrm{Nb}$-oxide-based precipitates.

\subsubsection{Summary of microstructure evolution results}


The several results presented above are summarized to emphasize the gist of the distinct microstructural features that formed as a function of $\mathrm{Nb}$ solute content and annealing temperature.

- $\mathrm{Cu}-1 \mathrm{Nb} / 400^{\circ} \mathrm{C}$ has only $\mathrm{Nb}$-oxide-based clusters and very little (0.03 at. \%) elemental $\mathrm{Nb}$ solute;

- $\mathrm{Cu}-5 \mathrm{Nb} / 400^{\circ} \mathrm{C}$ has elemental $\mathrm{Nb}$ segregation zones and $\mathrm{Nb}$-oxidebased clusters;

- $\mathrm{Cu}-10 \mathrm{Nb} / 400^{\circ} \mathrm{C}$ has $(\mathrm{NbO} \& \mathrm{NbN}$ )-based clusters, elemental $\mathrm{Nb}$ segregation zones and large elemental $(\mathrm{Nb})$-based precipitates; and

- $\mathrm{Cu}-1 \mathrm{Nb} / 800^{\circ} \mathrm{C}$ has only $\mathrm{Nb}$-oxide-based clusters whereas both $\mathrm{Cu}$ $5 \mathrm{Nb} / 800^{\circ} \mathrm{C}$ and $\mathrm{Cu}-10 \mathrm{Nb} / 800^{\circ} \mathrm{C}$ have both the $\mathrm{Nb}$-oxide-based precipitates and the large $(\mathrm{Nb}+\mathrm{Fe})$ precipitates.

\section{Discussion}

\subsection{Microstructure}

The low solute content alloys ( 1 at. $\% \mathrm{Nb}$ ) have similar microstructural features at both $400^{\circ} \mathrm{C}$ and $800^{\circ} \mathrm{C}$, i.e. Nb-oxide-based clusters at grain boundaries, Fig. 5 and 8 . Similar microstructure indicates that the initial phase

separation mechanism is the same regardless of the temperature. The only notable difference is that at $800^{\circ} \mathrm{C}$, these solute clusters are larger (approximately $3.5 \mathrm{~nm}$ vs. $2 \mathrm{~nm}$ ) suggesting that they are coarsened versions of the $\mathrm{Nb}$-oxide-based clusters formed at $400^{\circ} \mathrm{C}$. This size difference can easily be rationalized by faster kinetics at higher temperatures. As alluded to above, $\mathrm{Nb}$ oxide-based clusters form as a result of $\mathrm{Nb}$ solute reacting with the oxygen. This oxygen is believed to be associated with intrinsic contamination from the mechanical alloying process used to fabricate these alloys. The total oxygen content in each of the samples measured using APT is listed in Table 3. These $\mathrm{Nb}$-oxide-based clusters will form on the grain boundaries because of a reduced nucleation barrier [55] at the grain boundaries or the oxygen simply reacts with the $\mathrm{Nb}$ solute atoms that clustered within the boundaries. Once these clusters 
nucleate, the grain boundaries act as a Nb solute reservoir $[10,56]$ and oxygen acts as the limiting agent for the formation of these $\mathrm{Nb}$-oxide-based clusters. A similar formation of $\mathrm{Nb}$-oxide-based precipitates whose amount is limited by the amount of oxygen has been inferred in other studies [31]. However those Nboxide-based precipitates were never directly observed, due to the small size and low volume fraction [10], until now. In the alloys containing low Nb solute, i.e. 1 at. \% $\mathrm{Nb}$, all the $\mathrm{Nb}$ that segregated to the boundaries appeared to react with the oxygen.

Since $\mathrm{Cu}-1 \mathrm{Nb} / 400^{\circ} \mathrm{C}$ is the lowest solute content (1 at. \% Nb) and the lowest annealing temperature studied, its microstructure also represents the earliest stages of phase separation. Such solute clusters present along the grain boundary are consistent with experimental results on $\mathrm{Cu}$-Ta systems and molecular dynamics simulations [9, 25]. However, in this study the solute clusters in the grain boundaries react with oxygen and result in Nb-oxide-based clusters at the grain boundaries.

On increasing the solute content at $400^{\circ} \mathrm{C}, \mathrm{Cu}-5 \mathrm{Nb} / 400^{\circ} \mathrm{C}$, elemental $(\mathrm{Nb}+\mathrm{Fe})$ segregation zones are found in the vicinity of grain boundaries in addition to the $\mathrm{Nb}$-oxide-based clusters, Fig.6. This suggests the following sequence at 5 at. \% $\mathrm{Nb}$ solute concentration -1$) \mathrm{Nb}$ solute and oxygen form clusters limited by the amount of oxygen, 2) subsequently, the balance of elemental $\mathrm{Nb}$ atoms present segregate to form $(\mathrm{Nb}+\mathrm{Fe})$ zones. Comparing the size and the location of these elemental $(\mathrm{Nb}+\mathrm{Fe})$ segregation zones in $\mathrm{Cu}-5 \mathrm{Nb} / 400^{\circ} \mathrm{C}$ with respect to $\mathrm{Nb}$-oxidebased clusters, Fig. 6, and that of the clusters at grain boundaries in $\mathrm{Cu}$ $1 \mathrm{Nb} / 400^{\circ} \mathrm{C}$, Fig. 5 , it can be deduced that $\mathrm{Nb}$-oxide-based clusters at grain boundaries are likely the precursors of the phase separation. As the process continues, the grain boundaries accumulate more solute and begin to thicken, consistent with microstructure observations/predictions in other studies [8, 22, 23]. However, at the same solute content but at a higher annealing temperature, these segregation zones are not observed in $\mathrm{Cu}-5 \mathrm{Nb} / 800^{\circ} \mathrm{C}$; instead its microstructure is somewhat similar to $\mathrm{Cu}-10 \mathrm{Nb} / 400^{\circ} \mathrm{C}$ and their features are discussed below. 
$\mathrm{Cu}-5 \mathrm{Nb} / 800^{\circ} \mathrm{C}$, Fig. 9, has large (approximately $\left.10 \mathrm{~nm}\right)(\mathrm{Nb}+\mathrm{Fe})$ precipitates with a composition consistent with the $\mathrm{Fe}_{2} \mathrm{Nb}$ phase (a stable high temperature phase) and $7 \mathrm{~nm}$-sized $\mathrm{Nb}$-oxide-based precipitates. Similarly, $\mathrm{Cu}-10 \mathrm{Nb} / 400^{\circ} \mathrm{C}$, Fig.7, has large (approximately $12 \mathrm{~nm}$ ) size $\mathrm{Nb}$-rich precipitates, smaller $\mathrm{Nb}$ oxide-based clusters, and elemental $(\mathrm{Nb}+\mathrm{Fe})$ segregation at the grain boundaries. The main difference between these two different stages (Cu$5 \mathrm{Nb} / 800^{\circ} \mathrm{C}$ vs. $\left.\mathrm{Cu}-10 \mathrm{Nb} / 400^{\circ} \mathrm{C}\right)$ is that $(\mathrm{Nb}+\mathrm{Fe})$ solute segregation zones were not found in $\mathrm{Cu}-5 \mathrm{Nb} / 800^{\circ} \mathrm{C}$. Therefore, the presence of these $\mathrm{Fe}_{2} \mathrm{Nb}$ precipitates indicates that the precipitation of $\mathrm{Fe}_{2} \mathrm{Nb}$ is energetically favorable compared to only the formation of $\mathrm{Nb}$-rich segregation zones at the grain boundaries at $800^{\circ} \mathrm{C}$.

\subsection{Grain size stability and strength}

Ideal thermodynamic segregation involves segregation of solute atoms to an interface and it is usually quantified by calculating interfacial excess which gives the number of atoms per unit area of the feature. The immiscible systems investigated in this study have solute clusters at the grain boundary or a thickening of grain boundaries with solute. These equilibrium phase diagrams are ineffective in reflecting the state of the microstructure. Another phenomenon which complicates the analysis and is a consequence of processing itself, is that the solute reacts with intrinsic contaminants $[53,57]$. In this case, the dominant effect was the formation of $\mathrm{Nb}$-oxide-based clusters due to $\mathrm{Nb}$ solute clusters reacting with the available oxygen. Regardless of the complications, $\mathrm{Cu}-\mathrm{Nb}$ alloys have demonstrated substantially suppressed grain growth at high temperatures, consistent with other studies [9].

In $\mathrm{Cu}-1 \mathrm{Nb} / 400^{\circ} \mathrm{C}$, the grain boundary has $\mathrm{Nb}$-oxide-based clusters on it. Even though the boundary is not completely covered, these clusters clearly provide grain size stability as the grain size is approximately 6 times smaller than that of the unalloyed $\mathrm{Cu}$. Since no elemental $\mathrm{Nb}$ is present, one can conclude that a Zener-based pinning or kinetic stabilization appears to be responsible. On increasing the solute content to 5 at. \%, one observes $(\mathrm{Nb}+\mathrm{Fe})$ segregation zones at the grain boundary in addition to the $\mathrm{Nb}$-oxide-based clusters and a grain size of approximately $8.5 \mathrm{~nm}$, which is about 20 times smaller than that of 
the unalloyed copper. This higher degree of reduced grain growth concomitant with the segregation zones in the vicinity of the grain boundaries indicates that these zones are also responsible for this reduced grain growth, consistent with nanocrystalline grain stabilization observed in Cu-10Ta [10]. We believe both a kinetic and thermodynamic stabilization is occurring at this composition.

On further increasing the solute to 10 at. $\%\left(\mathrm{Cu}-10 \mathrm{Nb} / 400^{\circ} \mathrm{C}\right)$, the grain size is approximately 29 times smaller than that of the unalloyed $\mathrm{Cu}$ and one observes large $\mathrm{Nb}$-rich precipitates and $\mathrm{Nb}$-rich segregation zones at grain boundaries. Here, the solute content is large enough to result in formation of a distinct second phase - Nb-rich precipitates - and forms a duplex nanostructure. Interestingly, the precipitation of these $\mathrm{Nb}$-rich precipitates does not result in a loss of nanocrystalline grain size, as had been noted in other studies[24]. However, our results are consistent with those of Cu-10at. \% Ta [10]. Specifically, the $(\mathrm{Nb}+\mathrm{Fe})$-rich segregation zone is retained even in the presence of $\mathrm{Nb}$-rich precipitates, Fig. 7 , in $\mathrm{Cu}-10 \mathrm{Nb} / 400^{\circ} \mathrm{C}$ and $\mathrm{Nb}$ segregation is one of the factors responsible for the reduced grain growth. In both the $\mathrm{Cu}-5 \mathrm{Nb}$ and $\mathrm{Cu}$ $10 \mathrm{Nb}$ samples, Fig. 6 and 7, Fe was also shown to be present with $\mathrm{Nb}$. However, Fe does not contribute thermodynamically to the stabilization because $\mathrm{Fe}$ is predicted to not lead to any reduction in grain boundary energy of $\mathrm{Cu}$ [58]. Therefore, at these solute concentrations and after annealing at $400^{\circ} \mathrm{C}$, the nanocrystalline stabilization seems to be a combination of kinetic and thermodynamic factors.

At the $400^{\circ} \mathrm{C}$ annealing temperature, most of the strength in the material is due to grain size strengthening, Fig. 4, suggesting that the clusters in $\mathrm{Cu}-1 \mathrm{Nb}$ and the $\mathrm{Nb}$-rich precipitates in $\mathrm{Cu}-10 \mathrm{Nb}$ do not play a dominant role in strengthening. Also, the $\sim 20 \mathrm{~nm} \mathrm{Nb}$-rich precipitates would be too large to provide any Orowan strengthening.

After annealing at $800^{\circ} \mathrm{C}$, the unalloyed $\mathrm{Cu}$ has a grain size of $566 \mathrm{~nm}$ and by adding 1 at. \% $\mathrm{Nb}$ the grain size is reduced to $72 \mathrm{~nm}$. As the amount of solute is increased from 1 at. \% to 10 at. \%, the grain size further decreases from $72 \mathrm{~nm}$ to $33 \mathrm{~nm}$, Table 2. In $\mathrm{Cu}-1 \mathrm{Nb} / 800^{\circ} \mathrm{C}$, the grain boundary has only $\mathrm{Nb}$-oxide- 
based precipitates on it. Even though the boundary is not completely covered, these clusters again are sufficient to provide grain size stability as the grain size is approximately 7.6 times smaller than that of the unalloyed $\mathrm{Cu}$. On increasing the solute content to 5 at. \%, one observes $\mathrm{Nb}$-rich segregation zones at the grain boundaries in addition to the $\mathrm{Nb}$-oxide-based precipitates and a grain size of approximately $40 \mathrm{~nm}$, which is about 14 times smaller than that of the unalloyed copper, Fig. 3. On further increasing the solute to 10 at. \%, there is little difference in the stabilized grain size or the microstructure. At $400^{\circ} \mathrm{C}$, an increase in solute content appeared to have a greater influence on the stabilized grain size than at $800^{\circ} \mathrm{C}$, Fig. 3 . This may be associated with the fact that at $400^{\circ} \mathrm{C}$ elemental $\mathrm{Nb}$ segregation zones are retained along with precipitates providing both kinetic and thermodynamic stabilization (Fig. $6 \& 7$ ), whereas at $800^{\circ} \mathrm{C}$ only precipitates (and no segregation zones) are present (Fig. 9). Regardless the grains still show remarkably retarded grain growth compared to the unalloyed $\mathrm{Cu}$ control.

At the $800^{\circ} \mathrm{C}$ anneal, the strength of the 5 and 10 at. $\% \mathrm{Nb}$ was about $50 \%$ attributed to the grain size. The other strengthening mechanism is attributed to the secondary precipitation strengthening by the $\mathrm{Nb}$-enriched second phase in the microstructure.

\section{Conclusions}

This work has shown that mechanically alloying $\mathrm{Cu}$ with $\mathrm{Nb}$ improves nanocrystalline stability in the annealing temperature range of $400^{\circ} \mathrm{C}-800^{\circ} \mathrm{C}$. Increasing the $\mathrm{Nb}$ solute content resulted in reduced grain growth regardless of the annealing temperature. At the lowest solute concentration (1 at.\%), nearly all the elemental $\mathrm{Nb}$ reacted with oxygen (and other impurities) forming nanoscale $\mathrm{Nb}$-oxide-based clusters that were apparently along the grain boundaries providing kinetic stabilization. For the 5 and 10 at.\% $\mathrm{Nb}$, both $\mathrm{Nb}$-oxide-based clusters and elemental $\mathrm{Nb}$ were present along the grain boundaries. Depending on the solute concentration and annealing temperature, the $\mathrm{Nb}$ formed either $\mathrm{Nb}$ enriched segregation zones or $\mathrm{Nb}$-rich secondary precipitates. These 
microstructural features reduced the degree of grain growth via both kinetic and thermodynamic stabilization.

In this study, identifying the dominant stabilization mechanism was confounded by the presence of $\mathrm{Nb}$-oxide-based clusters, which formed from intrinsic impurities of the mechanical alloying process itself. This existence of impurity-driven clusters providing kinetic stabilization has also recently been recognized and discussed in a couple of studies $[53,57]$. Therefore, this work specifically used APT to understand nanocrystalline behavior in light of such impurities.

Scientifically, the ability to process bulk nanocrystalline materials free from impurities poses a challenge to the research community. From a practical standpoint, impurities are often present in industrial materials and their influence even in small amounts plays a significant role in defining microstructural evolution and physical properties. The understanding of the role of such impurities on stabilization will be especially important during industrial scale processing and commercialization of bulk nanocrystalline metals. Therefore, it is imperative that future studies on nanocrystalline stabilization identify and characterize these other contributors to stability to develop a comprehensive understanding of the stabilization mechanisms.

From a practical perspective, the $\mathrm{Cu}-\mathrm{Nb}$ alloy provides impressive strength $>1$ $\mathrm{GPa}$ that demonstrates stability at elevated temperatures. With an optimal $\mathrm{Nb}$ concentration of $\sim 5$ at.\% $\mathrm{Nb}$, the electrical conductivity of the alloy likely enables applications as a conductor or electrical contact material for high-temperature service. The alloy, for example, could provide an alternative to hazardous beryllium-copper alloys (e.g. Cu-2.5Be, UNS C17200).

\section{Acknowledgements}

MK, BLB and GBT were supported by the Materials Science and Engineering Division of the US Department of Energy, Office of Basic Energy Sciences. Sandia National Laboratories is a multi-program laboratory managed and operated by Sandia Corporation, a wholly owned subsidiary of Lockheed Martin 
Corporation, for the U.S. Department of Energy's National Nuclear Security Administration under contract DE-AC04-94AL85000. KD recognizes the Army Research Laboratory for his support. Finally TK was supported by Army Research Office, grant W911NF1310436.

\section{References}

[1] E. Hall. The deformation and ageing of mild steel: III discussion of results, Proceedings of the Physical Society. Section B 64 (1951) 747.

[2] N. Petch. The cleavage strength of polycrystals, J. Iron Steel Inst. 174 (1953) 2528.

[3] W.D. Callister, D.G. Rethwisch. Materials science and engineering: an introduction, Wiley New York, 2007.

[4] E. Botcharova, J. Freudenberger, L. Schultz. Mechanical and electrical properties of mechanically alloyed nanocrystalline $\mathrm{Cu}-\mathrm{Nb}$ alloys, Acta Materialia 54 (2006) 33333341 .

[5] P.C. Millett, R.P. Selvam, A. Saxena. Stabilizing nanocrystalline materials with dopants, Acta Materialia 55 (2007) 2329-2336.

[6] S. Özerinç, K. Tai, N.Q. Vo, P. Bellon, R.S. Averback, W.P. King. Grain boundary doping strengthens nanocrystalline copper alloys, Scripta Materialia 67 (2012) 720-723.

[7] K.A. Darling, M.A. Tschopp, R.K. Guduru, W.H. Yin, Q. Wei, L.J. Kecskes. Microstructure and mechanical properties of bulk nanostructured $\mathrm{Cu}-\mathrm{Ta}$ alloys consolidated by equal channel angular extrusion, Acta Materialia 76 (2014) 168-185.

[8] T. Chookajorn, C.A. Schuh. Thermodynamics of stable nanocrystalline alloys: A Monte Carlo analysis, Physical Review B 89 (2014).

[9] E. Botcharova, J. Freudenberger, L. Schultz. High thermal stability of mechanically-alloyed nanocrystalline $\mathrm{Cu}-\mathrm{Nb}$ alloys, Zeitschrift für Metallkunde 97 (2006) 1350-1354.

[10] K.A. Darling, A.J. Roberts, Y. Mishin, S.N. Mathaudhu, L.J. Kecskes. Grain size stabilization of nanocrystalline copper at high temperatures by alloying with tantalum, Journal of Alloys and Compounds 573 (2013) 142-150.

[11] H. Gleiter. Nanocrystalline materials, Springer, 1991. 
[12] M. Kapoor, G.B. Thompson. Role of atomic migration in nanocrystalline stability: Grain size and thin film stress states, Current Opinion in Solid State and Materials Science 19 (2015) 138-146.

[13] C.C. Koch, R.O. Scattergood, M. Saber, H. Kotan. High temperature stabilization of nanocrystalline grain size: Thermodynamic versus kinetic strategies, Journal of Materials Research 28 (2013) 1785-1791.

[14] C.C. Koch, R.O. Scattergood, K.A. Darling, J.E. Semones. Stabilization of nanocrystalline grain sizes by solute additions, Journal of Materials Science 43 (2008) 7264-7272.

[15] T. Chookajorn, H.A. Murdoch, C.A. Schuh. Design of stable nanocrystalline alloys, Science 337 (2012) 951-954.

[16] G. Gottstein, L.S. Shvindlerman. Grain boundary migration in metals: thermodynamics, kinetics, applications, CRC press, 2009.

[17] J. Weissmüller. Alloy thermodynamics in nanostructures, Journal of Materials Research 9 (1994) 4-7.

[18] J. Weissmüller. Some basic notions on nanostructured solids, Materials Science and Engineering: A 179-180, Part 1 (1994) 102-107.

[19] J. Weissmüller. Alloy effects in nanostructures, Nanostructured Materials 3 (1993) 261-272.

[20] F. Liu, R. Kirchheim. Grain boundary saturation and grain growth, Scripta Materialia 51 (2004) 521-525.

[21] B. Färber, E. Cadel, A. Menand, G. Schmitz, R. Kirchheim. Phosphorus segregation in nanocrystalline $\mathrm{Ni}-3.6$ at.\% $\mathrm{P}$ alloy investigated with the tomographic atom probe (TAP), Acta Materialia 48 (2000) 789-796.

[22] T. Chookajorn, C.A. Schuh. Nanoscale segregation behavior and hightemperature stability of nanocrystalline W-20at.\% Ti, Acta Materialia 73 (2014) 128-138.

[23] T. Chookajorn, M. Park, C.A. Schuh. Duplex nanocrystalline alloys: Entropic nanostructure stabilization and a case study on W-Cr, Journal of Materials Research 30 (2015) 151-163.

[24] K.A. Darling, R.N. Chan, P.Z. Wong, J.E. Semones, R.O. Scattergood, C.C. Koch. Grain-size stabilization in nanocrystalline FeZr alloys, Scripta Materialia 59 (2008) 530-533. 
[25] T. Frolov, K.A. Darling, L.J. Kecskes, Y. Mishin. Stabilization and strengthening of nanocrystalline copper by alloying with tantalum, Acta Materialia 60 (2012) 21582168.

[26] A.J. Detor, C.A. Schuh. Tailoring and patterning the grain size of nanocrystalline alloys, Acta Materialia 55 (2007) 371-379.

[27] J.R. Trelewicz, C.A. Schuh. Grain boundary segregation and thermodynamically stable binary nanocrystalline alloys, Physical Review B 79 (2009) 094112.

[28] T. Rojhirunsakool, K.A. Darling, M.A. Tschopp, G.P. Purja Pun, Y. Mishin, R. Banerjee, L.J. Kecskes. Structure and thermal decomposition of a nanocrystalline mechanically alloyed supersaturated $\mathrm{Cu}-\mathrm{Ta}$ solid solution, MRS Communications 5 (2015) 333-339.

[29] H.A. Murdoch, C.A. Schuh. Estimation of grain boundary segregation enthalpy and its role in stable nanocrystalline alloy design, Journal of Materials Research 28 (2013) 2154-2163.

[30] D.G. Morris, M.A. Morris. Mechanical alloying of copper-BCC element mixtures, Scripta Metallurgica et Materiala 24 (1990) 1701-1706.

[31] E. Botcharova, J. Freudenberger, L. Schultz. Cu-Nb alloys prepared by mechanical alloying and subsequent heat treatment, Journal of Alloys and Compounds 365 (2004) 157-163.

[32] M. Demkowicz, R. Hoagland, J. Hirth. Interface structure and radiation damage resistance in Cu-Nb multilayer nanocomposites, Physical Review Letters 100 (2008) 136102.

[33] M.D. Abad, S. Parker, D. Kiener, M.M. Primorac, P. Hosemann. Microstructure and mechanical properties of CuxNb1-x alloys prepared by ball milling and high pressure torsion compacting, Journal of Alloys and Compounds 630 (2015) 117-125.

[34] E. Botcharova, M. Heilmaier, J. Freudenberger, G. Drew, D. Kudashow, U. Martin, L. Schultz. Supersaturated solid solution of niobium in copper by mechanical alloying, Journal of Alloys and Compounds 351 (2003) 119-125.

[35] M.K. Miller. Atom probe tomography: analysis at the atomic level, Springer Science \& Business Media, 2012.

[36] K.A. Darling, M. Kapoor, H. Kotan, B.C. Hornbuckle, S.D. Walck, G.B. Thompson, M.A. Tschopp, L.J. Kecskes. Structure and mechanical properties of $\mathrm{Fe}-\mathrm{Ni}-$ $\mathrm{Zr}$ oxide-dispersion-strengthened (ODS) alloys, Journal of Nuclear Materials 467, Part 1 (2015) 205-213. 
[37] D.J. Young. High temperature oxidation and corrosion of metals, Elsevier, 2008.

[38] E. Brandes, G. Brook. Smithells metals reference book, 1992, London, But.

[39] C.J. Marvel, P.R. Cantwell, M.P. Harmer. The critical influence of carbon on the thermal stability of nanocrystalline Ni-W alloys, Scripta Materialia 96 (2015) 45-48.

[40] C.J. Marvel, D. Yin, P.R. Cantwell, M.P. Harmer. The influence of oxygen contamination on the thermal stability and hardness of nanocrystalline $\mathrm{Ni}-\mathrm{W}$ alloys, Materials Science and Engineering: A 664 (2016) 49-57.

[41] B.D. Cullity, S.R. Stock. Elements of x-ray diffraction. 3rd ed., Prentice Hall, Upper Saddle River, NJ, 2001.

[42] K. Darling, B. VanLeeuwen, C. Koch, R. Scattergood. Thermal stability of nanocrystalline Fe-Zr alloys, Materials Science and Engineering: A 527 (2010) 35723580.

[43] P.J. Felfer, B. Gault, G. Sha, L. Stephenson, S.P. Ringer, J.M. Cairney. A new approach to the determination of concentration profiles in atom probe tomography, Microsc Microanal 18 (2012) 359-364.

[44] P. Felfer, A. Ceguerra, S. Ringer, J. Cairney. Applying computational geometry techniques for advanced feature analysis in atom probe data, Ultramicroscopy 132 (2013) 100-106.

[45] S.K. Samudrala, P.J. Felfer, V.J. Araullo-Peters, Y. Cao, X.Z. Liao, J.M. Cairney. New atom probe approaches to studying segregation in nanocrystalline materials, Ultramicroscopy 132 (2013) 158-163.

[46] J. Brons, G. Thompson. A comparison of grain boundary evolution during grain growth in fcc metals, Acta Materialia 61 (2013) 3936-3944.

[47] X. Zhou, X.-x. Yu, T. Kaub, R.L. Martens, G.B. Thompson. Grain Boundary Specific Segregation in Nanocrystalline Fe (Cr), Scientific Reports 6 (2016).

[48] D. Tabor. The hardness of solids, Review of Physics in Technology 1 (1970) 145.

[49] W.F. Smith, J. Hashemi. Foundations of materials science and engineering, Mcgraw-Hill Publishing, 2006.

[50] T.H. Courtney. Mechanical behavior of materials, Waveland Press, 2005.

[51] J. Freudenberger, E. Botcharova, L. Schultz. Formation of the microstructure in $\mathrm{Cu}-\mathrm{Nb}$ alloys, Journal of Materials Science 39 (2004) 5343-5345. 
[52] M.A. Meyers, A. Mishra, D.J. Benson. Mechanical properties of nanocrystalline materials, Progress in Materials Science 51 (2006) 427-556.

[53] B.G. Clark, K. Hattar, M.T. Marshall, T. Chookajorn, B.L. Boyce, C.A. Schuh. Thermal Stability Comparison of Nanocrystalline Fe-Based Binary Alloy Pairs, JOM (2016) 1-9.

[54] O.C. Hellman, J.A. Vandenbroucke, J. Rüsing, D. Isheim, D.N. Seidman. Analysis of three-dimensional atom-probe data by the proximity histogram, Microscopy and Microanalysis 6 (2000) 437-444.

[55] D.A. Porter, K.E. Easterling, M. Sherif. Phase Transformations in Metals and Alloys, (Revised Reprint), CRC press, 2009.

[56] N.Q. Vo, S.W. Chee, D. Schwen, X. Zhang, P. Bellon, R.S. Averback. Microstructural stability of nanostructured $\mathrm{Cu}$ alloys during high-temperature irradiation, Scripta Materialia 63 (2010) 929-932.

[57] S.N. Mathaudhu, B.L. Boyce. Thermal Stability: The Next Frontier for Nanocrystalline Materials, JOM 67 (2015) 2785-2787.

[58] N.Q. Vo, J. Schäfer, R.S. Averback, K. Albe, Y. Ashkenazy, P. Bellon. Reaching theoretical strengths in nanocrystalline $\mathrm{Cu}$ by grain boundary doping, Scripta Materialia 65 (2011) 660-663. 


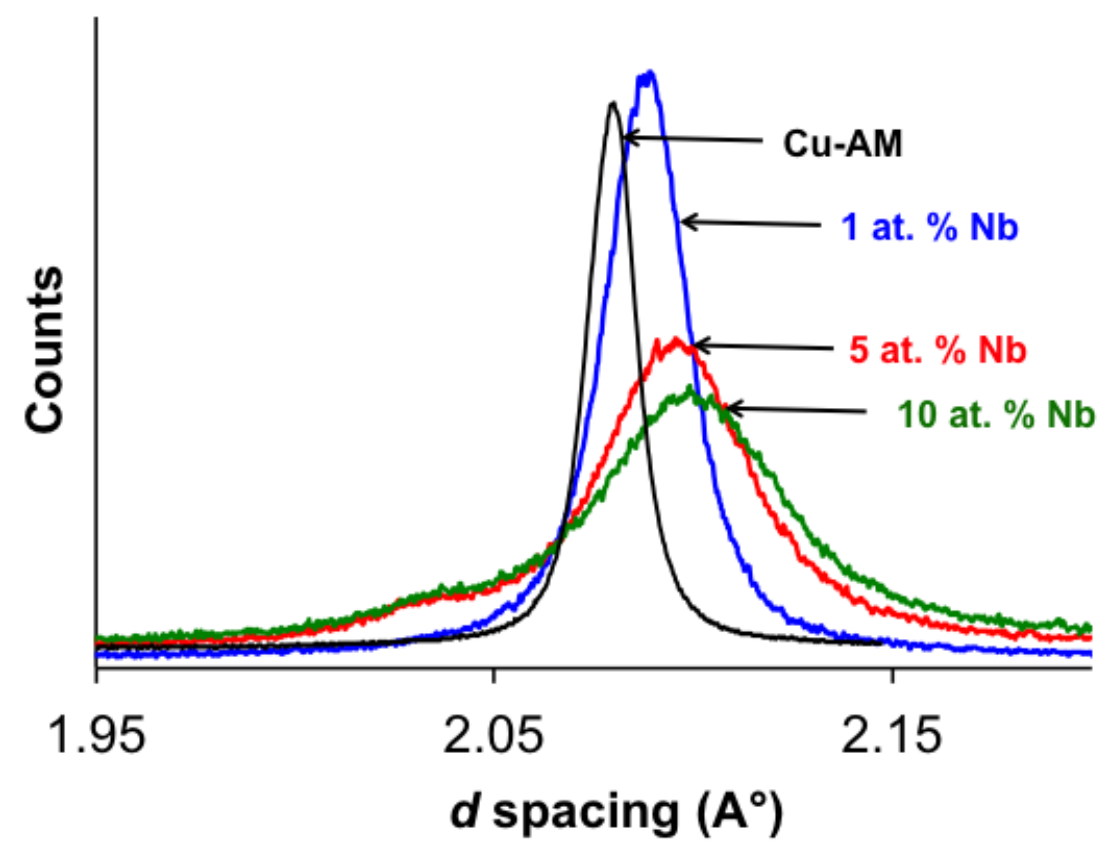

(a)

Fig. 1 - X-ray diffraction results of non-annealed (a) as-milled $\mathrm{Cu}$ and $\mathrm{Cu}-\mathrm{Nb}$ alloys with 1,5 and 10 at. \% $\mathrm{Nb}$, and (b) non-annealed 5 at. $\% \mathrm{Nb}, 5 \mathrm{Nb} / 400^{\circ} \mathrm{C}$ and $5 \mathrm{Nb} / 800^{\circ} \mathrm{C}$. The broken line in Fig. 1 (b) represents the $2 \theta$ position of unalloyed $\mathrm{Cu}(111)$ peak. 


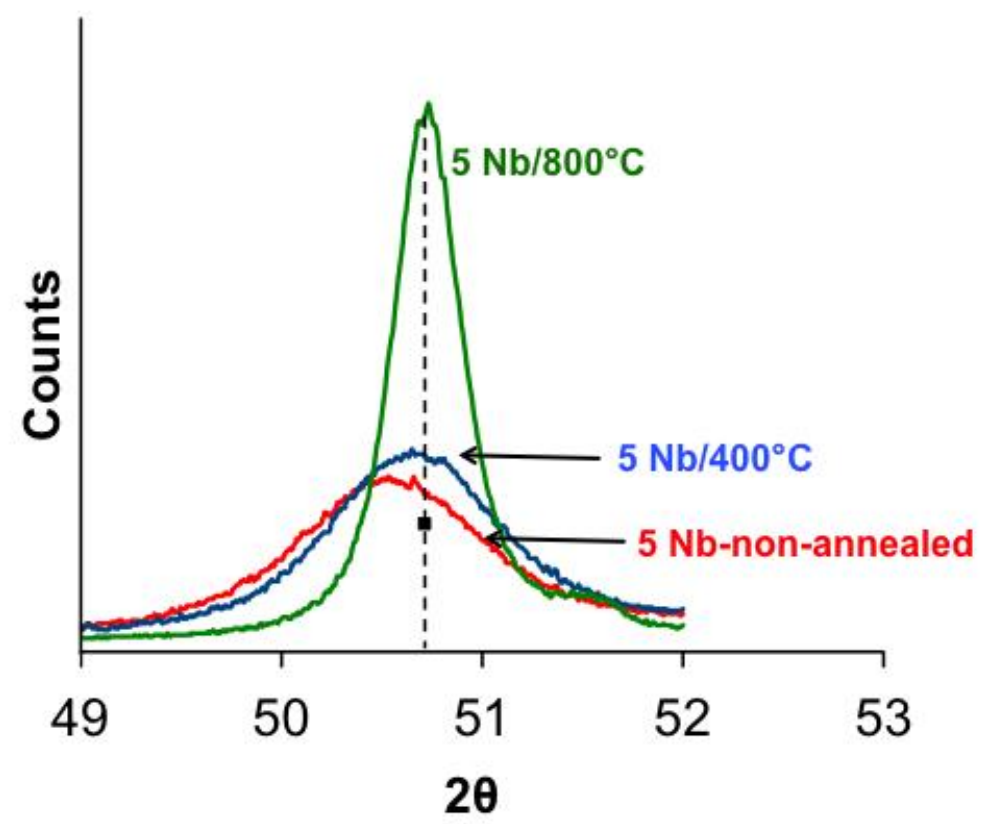

(b)

Fig. 1 - X-ray diffraction results of non-annealed (a) as-milled $\mathrm{Cu}$ and $\mathrm{Cu}-\mathrm{Nb}$ alloys with 1,5 and 10 at. \% $\mathrm{Nb}$, and (b) non-annealed 5 at. $\% \mathrm{Nb}, 5 \mathrm{Nb} / 400^{\circ} \mathrm{C}$ and $5 \mathrm{Nb} / 800^{\circ} \mathrm{C}$. The broken line in Fig. 1 (b) represents the $2 \theta$ position of unalloyed $\mathrm{Cu}(111)$ peak. 


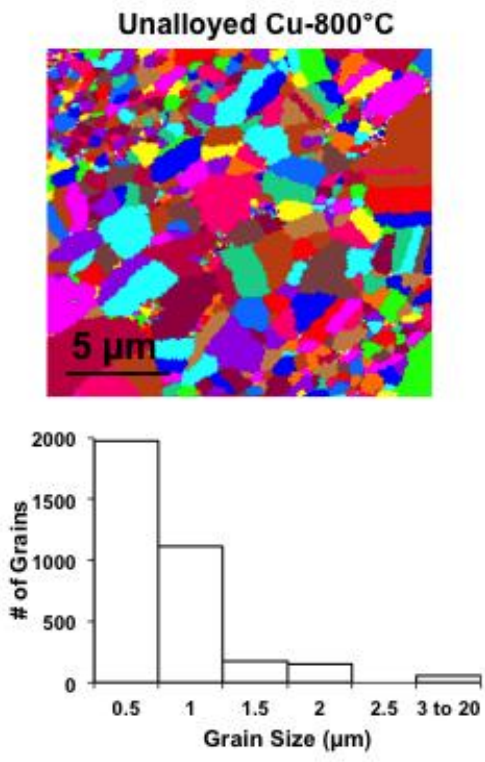

(a)
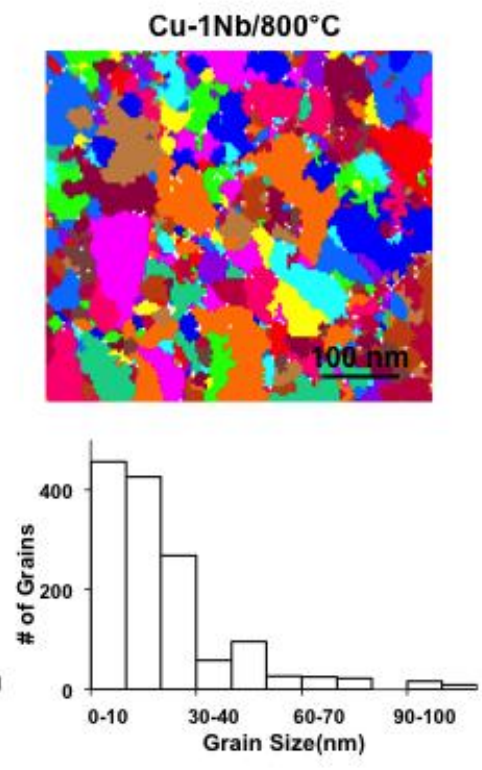

(b)
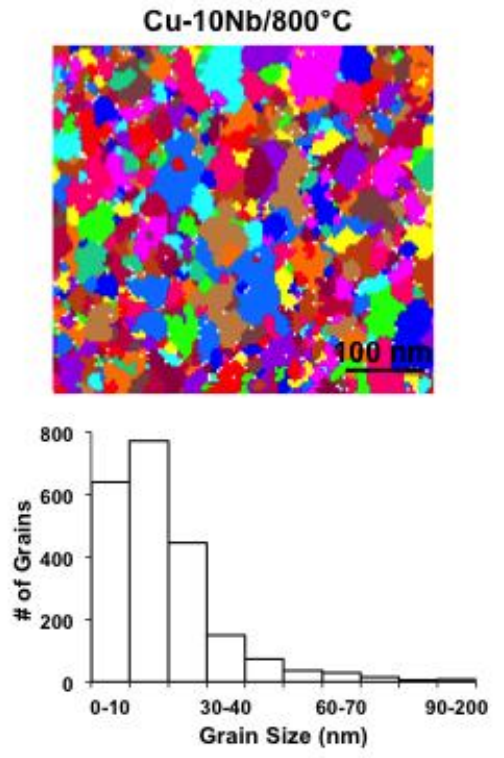

(c)

Fig. 2 - Electron backscatter diffraction of (a) unalloyed $\mathrm{Cu}$ and precession electron diffraction of (b) Cu-1Nb, and (c) $\mathrm{Cu}-10 \mathrm{Nb}$ annealed at $800^{\circ} \mathrm{C}$ for $1 \mathrm{hr}$. The images in the bottom row are the respective grain size distributions. 


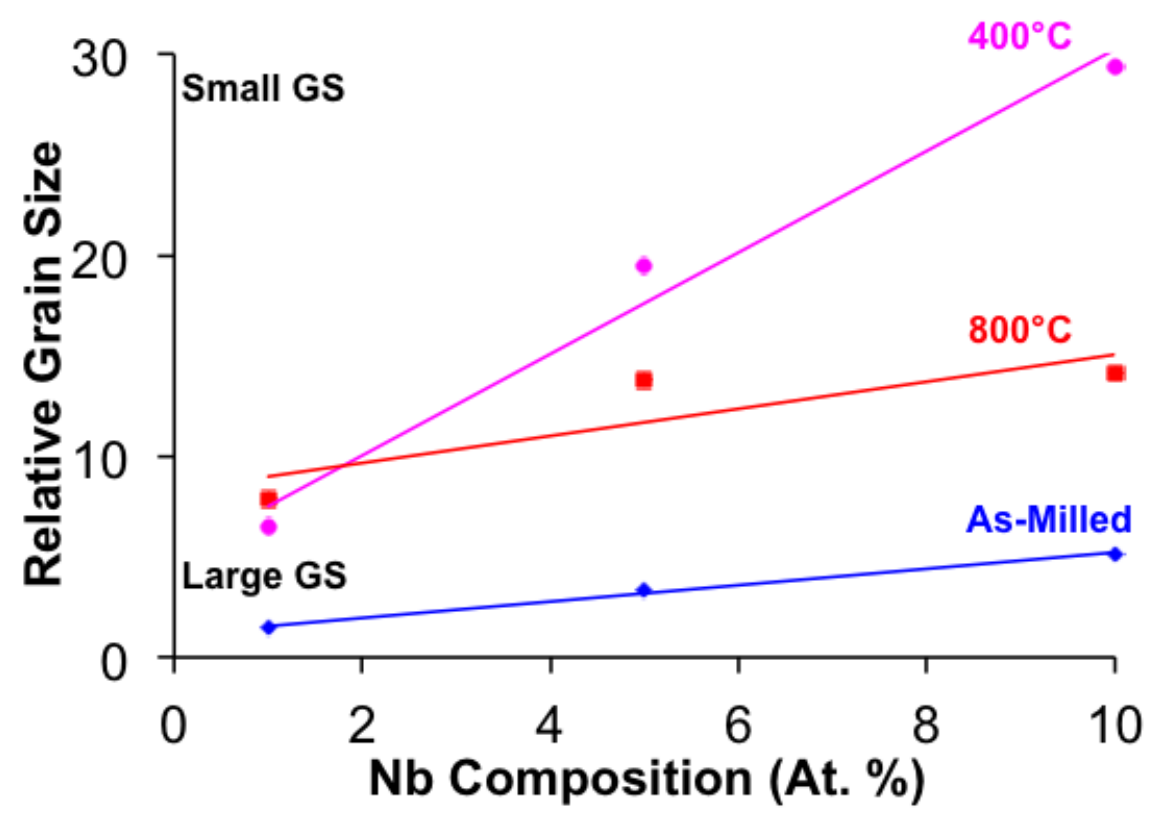

Fig. 3 - Effect of annealing temperature on grain size stabilization as a function of $\mathrm{Nb}$ composition. Relative grain size (GS) is the grain size of unalloyed Cu divided by that of alloyed $\mathrm{Cu}$. The lines are drawn only to guide the eye and not to infer a linear fit. 


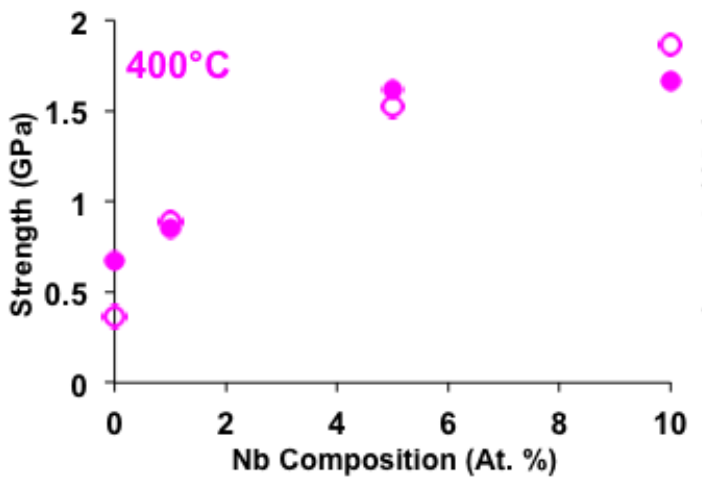

(a)

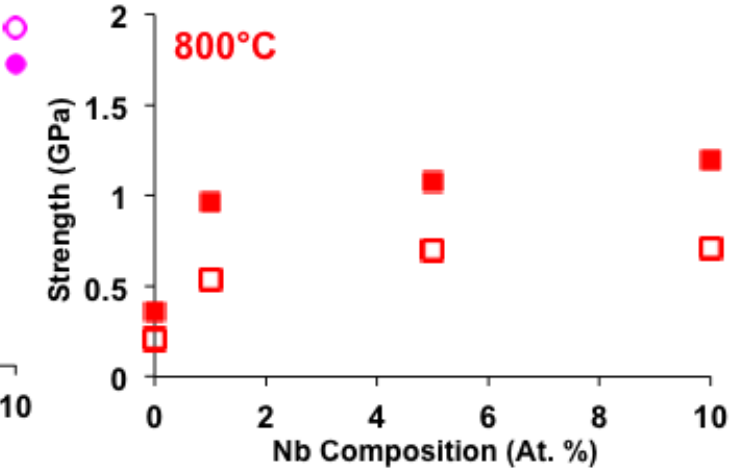

(b)

Fig. 4 - Strength as a function of $\mathrm{Nb}$ composition for the $\mathrm{Cu}-\mathrm{Nb}$ alloys annealed at (a) $400^{\circ} \mathrm{C}$ and (b) $800^{\circ} \mathrm{C}$ for $1 \mathrm{hr}$. The filled symbols represents the measured values converted to strength from Vickers Hardness and empty symbols represent the calculated Hall-Petch strength due to grain size. The HallPetch constants used are $25 \mathrm{MPa}$ and $0.137 \mathrm{MPa} \vee \mathrm{m}$. 


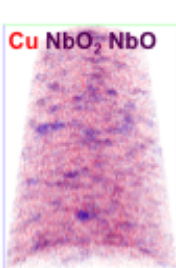

$\stackrel{30 \mathrm{~nm}}{\longleftrightarrow}$

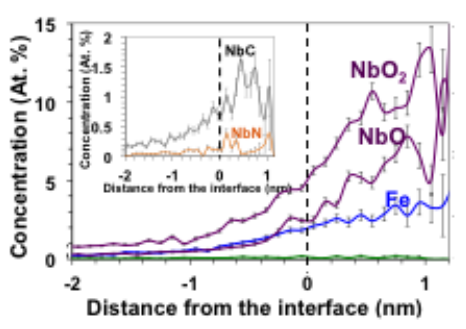

(b)

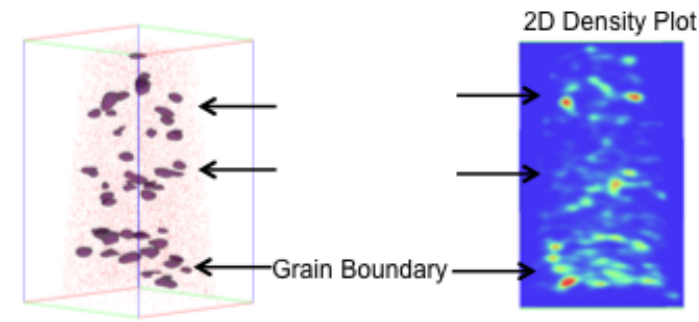

(c)

Fig. 5 - (a) Atom map from APT of $\mathrm{Cu}-1 \mathrm{Nb} / 400^{\circ} \mathrm{C}$ showing Nb-oxide-based clusters, (b) proximity histogram of 6 at. \% $\left(\mathrm{NbO}+\mathrm{NbO}_{2}\right)$ isoconcentration surface and 1 at. $\%(\mathrm{NbC}+\mathrm{NbN})$ (shown in inset) to illustrate the distribution of the clusters in the atom map, (c) $2 \mathrm{D}$ density plots of $\left(\mathrm{Fe}+\mathrm{NbO}+\mathrm{NbO}_{2}\right)$ along $\mathrm{x}-$ axis and $y$-axis of the reconstruction to delineate the areas of high density. 
(a)

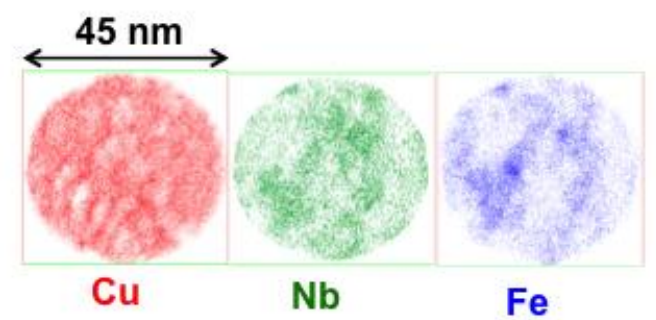

(b)
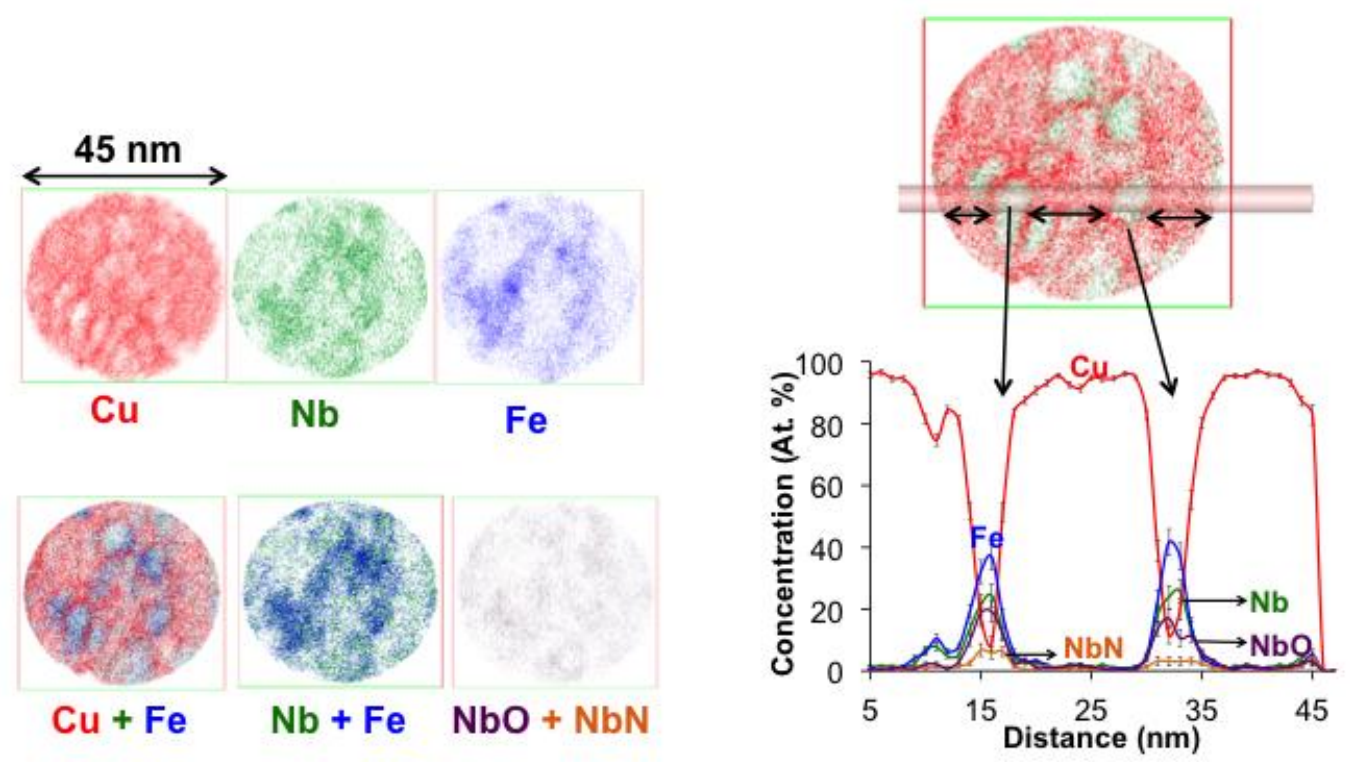

(c)

Fig. 6 - (a) Atom maps from APT in $\mathrm{Cu}-5 \mathrm{Nb} / 400^{\circ} \mathrm{C} \mathrm{Cu}, \mathrm{Nb}$ and $\mathrm{Fe}$, (b) mixed maps of $(\mathrm{Cu}+\mathrm{Fe}),(\mathrm{Nb}$ $+\mathrm{Fe})$ and $(\mathrm{NbO}+\mathrm{NbN})$, and (c) $1 \mathrm{D}$ composition profile obtained through the atom map with the cylinder showing the region through which the profile was obtained, and (d) Proximity histogram of 8 at. \% ( $\mathrm{NbO}$ $+\mathrm{NbO}_{2}$ ) isoconcentration surface to illustrate the co-existence of $\mathrm{Nb}$ solute with that of $\mathrm{NbO}$ clusters. 


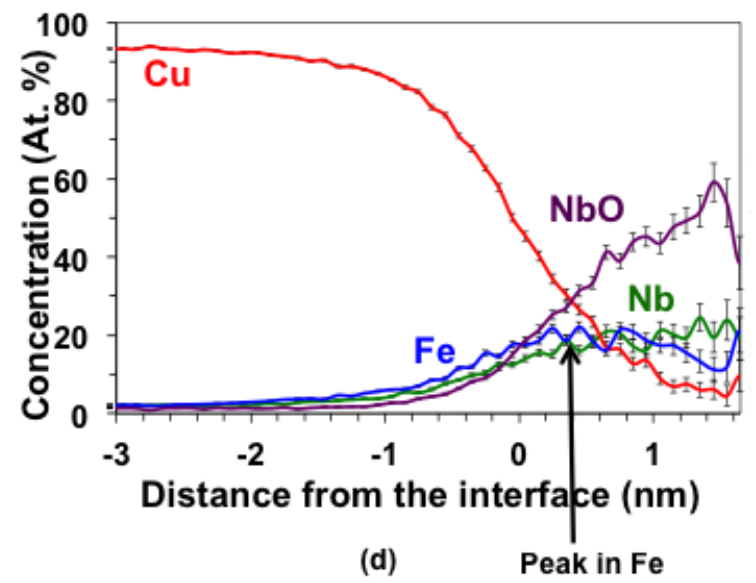

Fig. 6 - (a) Atom maps from APT in $\mathrm{Cu}-5 \mathrm{Nb} / 400^{\circ} \mathrm{C} \mathrm{Cu}, \mathrm{Nb}$ and $\mathrm{Fe}$, (b) mixed maps of (Cu+Fe), ( $\mathrm{Nb}$ $+\mathrm{Fe})$ and $(\mathrm{NbO}+\mathrm{NbN})$, and (c) 1D composition profile obtained through the atom map with the cylinder showing the region through which the profile was obtained, and (d) Proximity histogram of 8 at. \% (NbO $+\mathrm{NbO}_{2}$ ) isoconcentration surface to illustrate the co-existence of $\mathrm{Nb}$ solute with that of $\mathrm{NbO}$ clusters. 


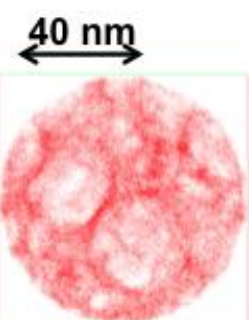

$\mathrm{Cu}$

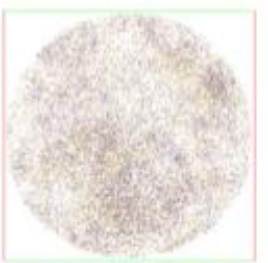

$\mathrm{NbO}+\mathrm{NbN}$

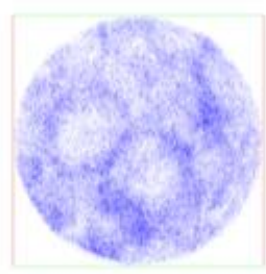

$\mathrm{Fe}$

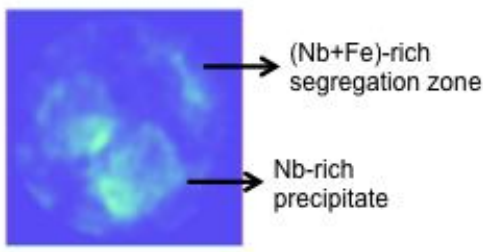

Nb Density map

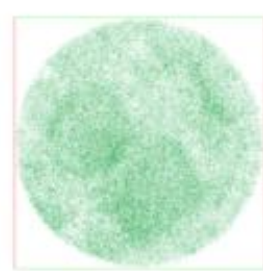

$\mathrm{Nb}$

(a)

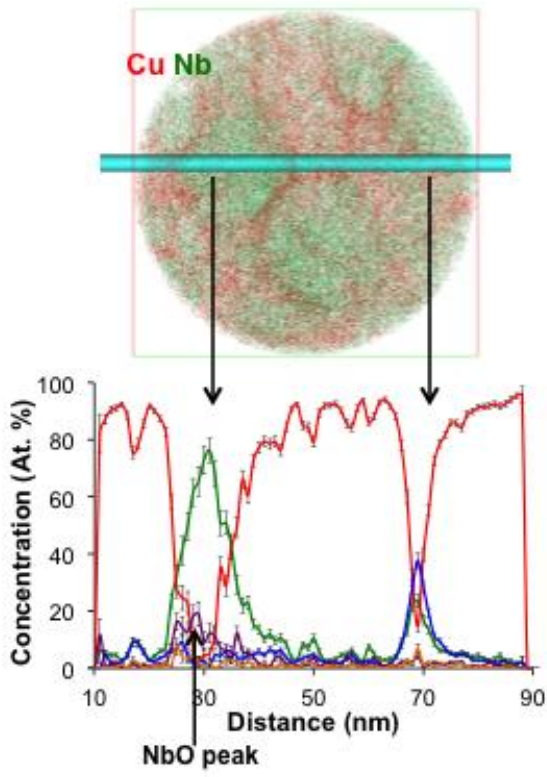

(b)

Fig. 7 - (a) Atom maps from APT of $\mathrm{Cu}-10 \mathrm{Nb} / 400^{\circ} \mathrm{C}$ showing $\mathrm{Cu}, \mathrm{Fe}, \mathrm{Nb},(\mathrm{NbO}+\mathrm{NbN})$ and $2 \mathrm{D}$ density map of $\mathrm{Nb}$; (b) $1 \mathrm{D}$ composition profile obtained through the atom map with the cylinder showing the region through which the profile was obtained. 


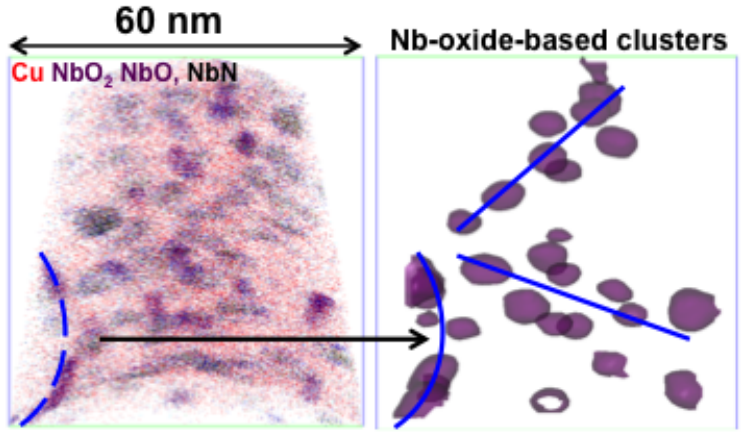

(a)

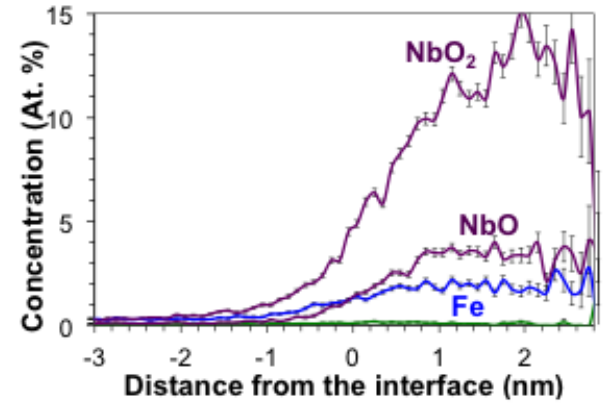

(c)

Fig. 8 - (a) Atom map from APT of $\mathrm{Cu}-1 \mathrm{Nb} / 800^{\circ} \mathrm{C}$ showing only $\mathrm{Cu}, \mathrm{NbO}_{2}, \mathrm{NbO}$ and $\mathrm{NbN}$ ions, (b) 6 at. $\%\left(\mathrm{NbO}_{2}+\mathrm{NbO}\right)$ isoconcentration surface only, and (c) proximity histogram of these clusters showing that they are $\mathrm{Nb}$-oxide-based clusters. 


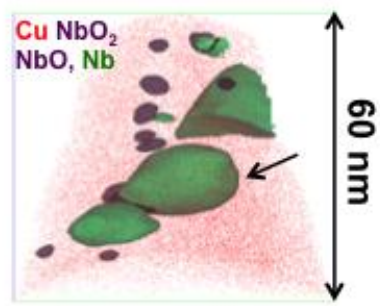

(a)

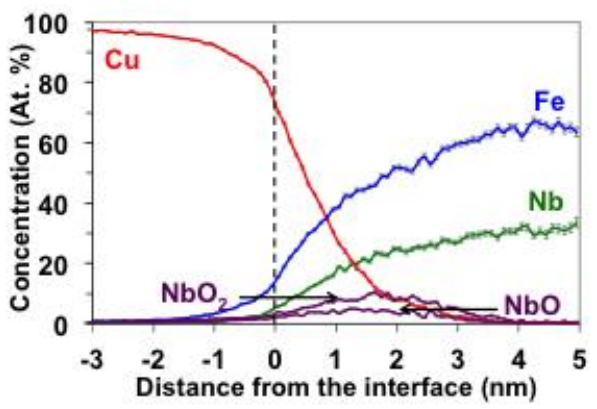

(c)

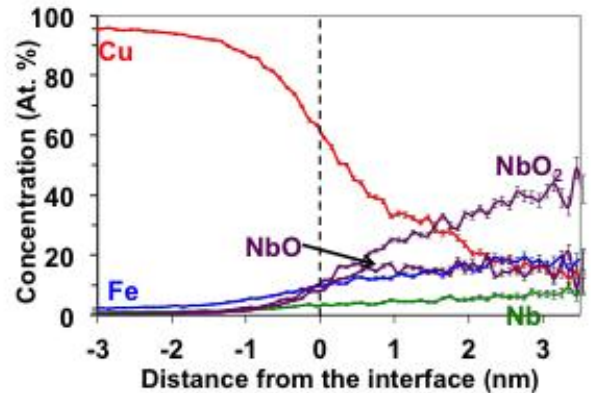

(b)

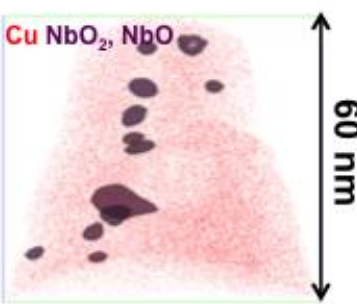

(d)

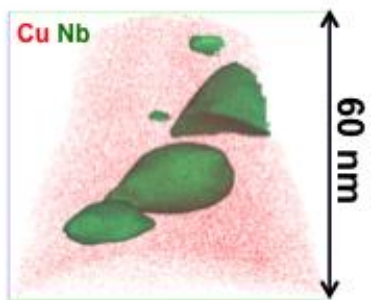

(e)

Fig. 9 - (a) Atom map from $\mathrm{Cu}-5 \mathrm{Nb} / 800^{\circ} \mathrm{C}$ showing Nb-oxide-based precipitates (purple) and ( $\left.\mathrm{Nb}+\mathrm{Fe}\right)$ based (green) large precipitates delineated by 8 at. \% $\left(\mathrm{NbO}_{2}+\mathrm{NbO}\right)$ and 20 at. $\%(\mathrm{Nb}+\mathrm{Fe})$ isoconcentration surfaces. Proximity histograms obtained from (b) 8 at. \% $\left(\mathrm{NbO}_{2}+\mathrm{NbO}\right)$, and (c) 20 at. \% (Nb+Fe) isoconcentration surfaces, (d) only 8 at. $\%\left(\mathrm{NbO}_{2}+\mathrm{NbO}\right)$, and $(\mathrm{e})$ only 20 at. $\%(\mathrm{Nb}+\mathrm{Fe})$ isoconcentration surfaces shown for clarity. Only $1 \% \mathrm{Cu}$ atoms are shown in atom maps. 
Table 1 : Alloy composition (at. \%) along with the annealing temperature $\left({ }^{\circ} \mathrm{C}\right)$. All the alloys were annealed for one hour.

\begin{tabular}{|c|c|c|c|c|}
\hline $\begin{array}{c}\text { Annealing Temperature } \\
\left({ }^{\circ} \mathbf{C}\right)\end{array}$ & $\mathbf{C u}$ & $\mathbf{C u}-1 \mathbf{N b}$ & $\mathbf{C u}-5 \mathrm{Nb}$ & $\mathbf{C u}-10 \mathrm{Nb}$ \\
\hline & & & & \\
\hline As-Milled & $\mathrm{Cu}-\mathrm{AM}$ & $\mathrm{Cu}-1 \mathrm{Nb}-\mathrm{AM}$ & $\mathrm{Cu}-5 \mathrm{Nb}-\mathrm{AM}$ & $\mathrm{Cu}-10 \mathrm{Nb}-\mathrm{AM}$ \\
\hline 400 & $\mathrm{Cu}-400$ & $\mathrm{Cu}-1 \mathrm{Nb}-400^{\circ} \mathrm{C}$ & $\mathrm{Cu}-5 \mathrm{Nb}-400^{\circ} \mathrm{C}$ & $\mathrm{Cu}-10 \mathrm{Nb}-400^{\circ} \mathrm{C}$ \\
\hline 800 & $\mathrm{Cu}-800$ & $\mathrm{Cu}-1 \mathrm{Nb}-800^{\circ} \mathrm{C}$ & $\mathrm{Cu}-5 \mathrm{Nb}-800^{\circ} \mathrm{C}$ & $\mathrm{Cu}-10 \mathrm{Nb}-800^{\circ} \mathrm{C}$ \\
\hline
\end{tabular}

Table 2 (a): Grain sizes (nm) of Cu-Nb alloys obtained from XRD data from $\mathrm{Cu}$ (111), (200), and (220) peaks.

\begin{tabular}{|c|c|c|c|c|}
\hline $\begin{array}{c}\text { Annealing Temperature } \\
\left({ }^{\circ} \mathbf{C}\right)\end{array}$ & $\mathbf{C u}$ & $\mathbf{C u}-\mathbf{1 N b}$ & $\mathbf{C u}-5 \mathrm{Nb}$ & $\mathbf{C u}-\mathbf{1 0 N b}$ \\
\hline As-Milled & $24.0 \pm 14.2$ & $16.6 \pm 6.8$ & $7.1 \pm 2.6$ & $4.7 \pm 1.8$ \\
\hline 400 & $43.1 \pm 13.4$ & $25.2 \pm 16.1$ & $8.4 \pm 2.9$ & $5.5 \pm 2.0$ \\
\hline 800 & $547.0 \pm 570.0$ & $72.2 \pm 22.1$ & $41.1 \pm 15.3$ & $40.0 \pm 16.1$ \\
\hline
\end{tabular}

Table 2 (b): Grain sizes (nm) of Cu obtained from EBSD and of $\mathrm{Cu}-\mathrm{Nb}$ alloys obtained from PED.

\begin{tabular}{|c|c|c|c|c|}
\hline & $\mathbf{C u}$ & $\mathbf{1 N b}$ & $\mathbf{5 N b}$ & $\mathbf{1 0 N b}$ \\
\hline $\mathbf{4 0 0}^{\circ} \mathbf{C}$ & $163 \pm 99$ & $17.6 \pm 13.9$ & $14.2 \pm 7.0$ & NA \\
\hline $\mathbf{8 0 0}^{\circ} \mathbf{C}$ & $566 \pm 778$ & $21.5 \pm 20.8$ & NA & $19.3 \pm 14.3$ \\
\hline
\end{tabular}

NA-Not analyzed.

Table 2 (c): Relative grain size of $\mathrm{Cu}-\mathrm{Nb}$ alloys obtained from EBSD results of $\mathrm{Cu}$ and $\mathrm{XRD}$ results of $\mathrm{Cu}-\mathrm{Nb}$ alloys.

\begin{tabular}{|c|c|c|c|}
\hline & $\mathbf{1 N b}$ & $\mathbf{5 N b}$ & $\mathbf{1 0 N b}$ \\
\hline $\mathbf{A M}$ & 1.4 & 3.4 & 5.1 \\
\hline $\mathbf{4 0 0} \mathbf{C}$ & 6.5 & 19.4 & 29.5 \\
\hline $\mathbf{8 0 0}^{\circ} \mathbf{C}$ & 7.8 & 13.8 & 14.1 \\
\hline
\end{tabular}

Table 3: Oxygen content (at. \%) measured using atom probe tomography.

\begin{tabular}{|c|c|c|c|}
\hline & \multicolumn{3}{|c|}{} \\
\hline & $\mathbf{1 0 N b}$ & $\mathbf{5 N b}$ & $\mathbf{1 N b}$ \\
\hline $\mathbf{A M}$ & $\mathrm{NA}$ & 0.92 & $\mathrm{NA}$ \\
\hline $\mathbf{4 0 0 ^ { \circ } \mathbf { C }}$ & 0.10 & 1.35 & 0.94 \\
\hline $\mathbf{8 0 0 ^ { \circ } \mathbf { C }}$ & 0.75 & 0.95 & 0.67 \\
\hline
\end{tabular}

NA - Not analyzed. 


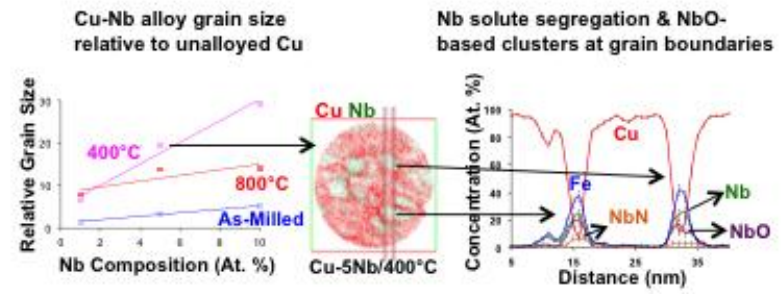

